\title{
Inhibition and anticipation in visual search: Evidence from effects of color foreknowledge on preview search
}

\author{
JASON J. BRAITHWAITE and GLYN W. HUMPHREYS \\ University of Birmingham, Birmingham, England
}

\begin{abstract}
We present four experiments in which we examined the effects of color mixing and prior target color knowledge on preview search (Watson \& Humphreys, 1997). The task was to detect a target letter (an $\mathrm{N}$ or a Z) that appeared along with other new letters, when old distractors remained in the visual field. In some conditions, participants were told the target's color; in others, they were not. Foreknowledge of the target's color produced large improvements in search for both baseline and preview presentations (Experiment 1). For preview presentations, the magnitude of this effect was reduced if the target shared its color with a single colored set of previewed letters (Experiment 2). Removing this similarity across the displays greatly improved search efficiency (Experiment 3). In Experiment 4, we assessed and rejected the proposal that the effects reflected the probability that the target was carried by a particular color. We discuss the results in terms of separate effects of (1) inhibitory carryover from a preview color group and (2) an anticipatory set for a known target color.
\end{abstract}

Our visual world is complex, diverse, and dynamic. The capacity of the nervous system is exceeded by such rich, detailed, and continuous sources of information (Allport, 1993; Broadbent, 1958; Neisser, 1967; Treue \& Martinez Trujillo, 1999). This limitation makes it necessary to prioritize selection so that objects relevant to behavioral goals are made available for action. The present study is concerned with establishing the mechanisms of prioritizing selection for new objects.

\section{Positive Attentional Set in Search}

Numerous studies now exist demonstrating the special status that new objects or events seem to enjoy in visual selection: New objects seem to receive greater priority for visual attention than do old items (Hillstrom \& Yantis, 1994; Yantis, 1996; Yantis \& Hillstrom, 1994; Yantis \& Johnston, 1990; Yantis \& Jonides, 1984). Although some researchers have suggested that this new-item advantage reflects an automatic process of prioritization, so that new items capture attention (e.g., Theeuwes, 1992, 1993, 1994, 1996; Yantis, 1993a, 1993b; see also Yantis, 1996, for a recent review), ${ }^{1}$ others have shown that this prioritization process can be influenced by the top-down attentional set

This research was supported by a Ph.D. studentship from the School of Psychology, University of Birmingham, awarded to the first author, and by a program grant for the MRC to the second author. We thank Chris Olivers for his continued assistance with programming the experiments reported here and Johan Hulleman for helpful suggestions. We also thank Kim Shapiro, Kyle Cave, and two anonymous reviewers for very helpful comments on an earlier version of this paper. Correspondence concerning this article should be addressed to J. J. Braithwaite, Behavioural Brain Sciences, School of Psychology, University of Birmingham, Edgbaston, Birmingham B15 2TT, England (e-mail: j.j.braithwaite@bham.ac.uk). adopted by the observer (Bacon \& Egeth, 1994; Folk \& Remington, 1996; Folk, Remington, \& Johnston, 1992, 1993; Folk, Remington, \& Wright, 1994; Gibson \& Kelsey, 1998; Yantis \& Egeth, 1999). Optimal capture of attention by new items is not determined purely by the presence of onsets or by the nature of the new event per se. To produce optimal capture by new objects, observers may have to adopt an anticipatory set in which strong weight is given to new information in any competition for selection.

Other evidence for top-down prioritization of selection comes from studies of visual search in which investigators have manipulated the ratios of the different distractor types presented in a typical display. For instance, Egeth, Virzi, and Garbart (1984) showed that, for conjunctively defined targets, search can be limited to only those distractors that share the relevant target-defining attribute-in their case, color. Bacon and Egeth (1997) and Moore and Egeth (1998) suggested that this form of guidance in search is based on the prioritized selection of items that share the relevant target feature, relative to items that do not. Owing to this prioritization process, attention is applied first to locations that have search-relevant feature dimensions (Bacon \& Egeth, 1997; Moore \& Egeth, 1998). These results for prioritized selection have typically been linked to positive effects of an attentional set, in which relevant features are given a competitive advantage by being preactivated (Bacon \& Egeth, 1997; Egeth et al., 1984; Folk et al., 1992, 1993; Folk et al., 1994; Kaptein, Theeuwes, \& van der Heijden, 1995; Moore \& Egeth, 1998).

\section{Negative Attentional Set in Search}

A contrasting view is that new objects are prioritized not only by adoption of a positive set for relevant target features, but also by adoption of a negative set toward old 
or irrelevant information. If old items are actively inhibited, new items may gain an additional competitive advantage for selection. This notion, that old items in search can be inhibited, was proposed by Watson and Humphreys (1997). Watson and Humphreys (1997) took a standard color-form conjunction search task (e.g., Treisman \& Gelade, 1980) and decomposed the presentation of items across two displays segregated by a $1-\mathrm{sec}$ preview interval. The first display contained only distractors of one color. The new display contained the second set of distractors plus the target (when present). Watson and Humphreys (1997) found that, in the preview condition, search was as efficient as when only the new items appeared alone (in a single-feature baseline condition) and that it was considerably more efficient than in a conjunction baseline, when both sets of distractors were presented simultaneously.

Watson and Humphreys (1997) argued that the search advantage in the preview condition occurred because old items were actively inhibited (via a process they termed visual marking). This inhibition was thought to depend on an intentional, resource-limited mechanism-an inhibitory template that links the to-be-ignored distractors. Direct evidence for inhibitory effects has been reported from studies using probe dot detection, where dots are difficult to detect when presented at the locations of old items (Olivers \& Humphreys, 2002; Watson \& Humphreys, 2000). That this effect is intentional is shown by the fact that inhibited probe detection is found only when observers are engaged in search for new targets; it does not occur when probe detection alone is performed (Olivers \& Humphreys, 2002; Watson \& Humphreys, 2000). Furthermore, the efficient selection of new targets is reduced when observers perform a demanding secondary task during the preview interval, when only the old items are present (Humphreys, Watson, \& Jolicœur, 2002; Olivers \& Humphreys, 2002; Watson \& Humphreys, 1997). Indeed, when a secondary task is introduced (presumably removing inhibition), probe detection at the location of old items actually improves (Olivers \& Humphreys, 2002).

In the original paper, Watson and Humphreys (1997) proposed that, for static displays, marking was location based and did not consider the featural properties of the to-be-ignored items. That is, marking was, in essence, feature blind. However, when the items moved, inhibition could be mediated in a feature-based manner (Watson \& Humphreys, 1998; see also Olivers, Watson, \& Humphreys, 1999, and Theeuwes, Kramer, \& Atchley, 1998, for supportive evidence with heterogeneous displays). More recent evidence, however, has demonstrated that the featural properties of the old items (e.g., their color and orientation) are important even with static displays. This raises the question of whether the locationbased inhibitory template is feature blind in this instance. For example, Olivers and Humphreys (2002) interspersed standard preview trials with trials in which no preview was presented but the search display had the same color as the previously ignored preview. Search was slow to such displays, but this cost was reduced if participants engaged in a secondary task when the earlier preview was present. This is consistent with inhibition's being carried over on the basis of feature similarity between displays, with inhibition being reduced under task conditions (see also Gibson \& Jiang, 2001, for further evidence).

More recently, Braithwaite, Humphreys, and Hodsoll (2002) have reported a series of experiments that have shown a complex interactive role for color similarity in preview search, which they interpreted in terms of effects on both anticipatory (excitatory) and inhibitory sets. ${ }^{2}$ Braithwaite et al. (2002) orthogonally manipulated color homogeneity in preview search. There were preview conditions in which (1) all the first items were red and all the second items were green $(R+G),(2)$ all the first items were red and green and all the second items were green $(R G+G),(3)$ all the first items were red and all the second items were red and green $(R+R G)$, and (4) both sets of items were mixed red and green $(R G+R G)$. In the last two conditions, targets could be either red or green, and the participants did not know the color of the target prior to a trial. Braithwaite et al. (2002) found that preview search was facilitated when the new items had a common color (Conditions 1 and 2), relative to when they had two (or more) colors (Conditions 3 and 4). This was taken to suggest that the participants had adopted an anticipatory set for new items of a predesignated color. Furthermore, color similarity within Display 1 and between Displays 1 and 2 became important when an expectancy set for the target color could not be employed (e.g., when Display 2 had mixed colors: RG). Target discrimination was difficult when Display 1 had a single color that was also the color of the target in Display 2 (e.g., red targets in condition $\mathrm{R}+\mathrm{RG})$. This effect was attributed to colorbased inhibition (e.g., marking) of the old items, which could be carried over to targets of the same color in Display 2. Braithwaite et al. (2002) also observed effects of color similarity in Display 1 even when the new items differed in color, relative to the old (old items, yellow and blue or just blue; new items, red and green). This suggested that the selection of new items was enhanced when old distractors could be grouped and rejected on the basis of common color.

Collectively, these studies show that the preview benefit in search cannot be due solely to feature-blind inhibition of locations (e.g., the original suggestion from Watson \& Humphreys, 1997). Furthermore, it appears that selection and prioritization of new items is optimized not only by a positive expectation of their featural properties, but also by inhibition of old items. Participants seem to adopt both a positive set for a target color and an inhibitory set for old items (based on color as well as on location).

These results run counter to the idea that the preview benefit in search is due simply to the capture of attention by the new items (e.g., Donk \& Theeuwes, 2001). Donk and Theeuwes showed that the preview effect was abolished when new items were isoluminant with their back- 
ground and, so, did not appear as abrupt new onsets. They argued that new onsets were important for the effect because onsets capture attention. However, according to this account, new items in the preview condition should capture attention irrespective of whether these items are the same color and irrespective of whether they have the same color as or a different color from the old items. The evidence from Braithwaite et al. (2002) contradicts this.

The role of color in preview search was further assessed in the present research, in which we evaluated its influence on both the positive set for new targets and the inhibitory set for old distractors. We did this by varying whether the observers had foreknowledge of the target's color. In Braithwaite et al.'s (2002) experiments, foreknowledge of the target color was manipulated by having all the items in the second search display the same color (e.g., all green in the $R G+G$ and $R+G$ preview conditions). Here, we explored the role of color-based expectancies by using mixed color search sets in the second display but giving foreknowledge of which was the target's color. We then assessed whether this foreknowledge was equally effective irrespective of the color of the old items. That is, could a positive set for the target's color be modulated by an inhibitory set to the color of the old items?

\section{Overview of the Present Experiments}

Before describing the experiments, it will be useful to present a brief outline of the notation for experimental conditions. The baselines in Experiments 1 and 2 are described simply by name. Typically, two baselines were used. One was a full-set baseline, where all the letters present in the final display in the preview condition appeared simultaneously. This provided an estimate of performance in the preview condition if both the old and the new items were searched. This will be labeled as full. The second was a half-set baseline, where just the second set of letters from the preview display was presented. This provided an estimate of performance in the preview condition if only the new items were searched. This will be labeled as half. The preview conditions will be labeled in terms of the colors of the stimuli making up the first plus the second displays. For example, the label $\mathrm{R}+\mathrm{G}$ will be applied to a case in which the first set of stimuli (the old items) were red and the second set (the new items) were green. The label RG $+\mathrm{RG}$ will refer to preview conditions in which approximately half the old items were red and half green, and approximately half the new items were red and half green (see Experiment 1, Method section). For conditions in which prior knowledge of the target color was given, the label $p$ will be added. For instance, in condition RG + RGp, both the old and the new sets comprised a mixture of red and green letters, and the participants were given foreknowledge of the target color (green for half the participants, red for the others). In Experiments 2 and 3, we gave the participants foreknowledge of the target color and also manipulated whether this was the same color as or a different color from the preview. In this case, it is important to denote the expected color of the target (to signal whether it matched or failed to match the color of the preview). To do this, we will underline the expected color in the second set of items. For example, the label R + $\underline{\mathrm{R}} \mathrm{Gp}$ refers to a case in which the old items were red, the new items were a mixture of red and green letters, and the participants were told that the target was always red. Tables 1-3 summarize the conditions used in each experiment and their labels. For simplicity, throughout the paper, we refer to the target in the predicted color as being always red. Note, however, that the actual color of the known target was counterbalanced across participants so that, when it was always green, green was also the color of all the old items being ignored (e.g., $R+\underline{R G}=G+$ $\mathrm{RG})$. Thus, both conditions were identical in the sense that the color being prioritized was always the color of all the old items currently being ignored.

Four visual search experiments will be reported. Across all the experiments, displays consisted of heterogeneous distractor letter items $(\mathrm{H}, \mathrm{I}, \mathrm{V}$, and $\mathrm{X})$, with the target being either a $\mathrm{Z}$ or an $\mathrm{N}$. The participants made a forced-choice decision as to which target was present. Search through such letter sets is typically serial (Braithwaite et al., 2002; Theeuwes et al., 1998). The displays contained letters that could be colored either solely green or mixed (approximately half were red, half green). In some mixed-color displays, the target color was uncertain (it could be red or green on $50 \%$ of the occasions). Hence, in these conditions, color was irrelevant to the search task. However, in other conditions consisting of identical search displays, the participants were given explicit knowledge of the color group that the target would appear in. This knowledge was always $100 \%$ valid. This provided the incentive for the participants to set themselves (in anticipation) to search only the relevant colored second set of items when told to do so.

In Experiment 1, we sought to establish whether direct knowledge of the target color could aid preview search with the present stimuli. This was done by creating conditions with and without target color foreknowledge. There were six experimental conditions (see Table 1). Three of the conditions were baselines: (1) a single-color (green) half-set baseline (half), (2) a mixed-color (red and green) full-set baseline (full), and (3) a mixed-color full-set baseline where the participants were given prior knowledge of the color of the target (fullp). There were also three preview conditions: (4) a preview condition with all the first items mixed red and green and all the second items green $(R G+G),(5)$ a preview condition with both displays mixed red and green in color $(\mathrm{RG}+$ RG), and (6) a preview condition identical to (5), but with the participants given prior knowledge of the target color $(R G+\underline{R} G p ;$ see Table 1$)$.

Consider performance if search could be optimized for anticipated new targets of a particular color. In the $\mathrm{RG}+\underline{\mathrm{R}} \mathrm{Gp}$ condition in Experiment 1, both the preview 
Table 1

The Experimental Conditions, Color Combinations, and Target Colors for Experiment 1

\begin{tabular}{lcccl}
\hline Condition & Preview Display & Search Display & Foreknowledge & Target Color \\
\hline Half set & - & G & $\checkmark$ & green \\
Full set & - & RG & $\times$ & either (50\%) \\
Fullp & - & RG & $\checkmark$ & red (or green)* \\
RG + G & RG & G & $\checkmark$ & green \\
RG + RG & RG & RG & $\times$ & either (50\%) \\
RG + RGp & RG & RG & $\checkmark$ & red (or green)* \\
\hline
\end{tabular}

Note-The notation in the foreknowledge column refers to whether, in that individual condition, the observers were provided with foreknowledge (denoted by a $\checkmark$ ) or were not provided with foreknowledge (denoted by a $\times$ ). *Counterbalanced across participants.

and the second displays were mixed in color (but the target's color was known). For a display size of 24 items, 12 were presented in the first display, and 12 items in the second. In each display, approximately half the items were red, and approximately half were green. The numbers of red and green letters presented on a trial were randomly determined, with the proviso that at least one member of each color group was present. If search could be restricted to just the anticipated color subset, then reaction times (RTs) would, on average, be based on search through just half of the new items. However, in the preview $\mathrm{RG}+\mathrm{G}$ condition, all the new items (12 items for the same display size) were green, so even though the target's color could still be anticipated, search would be through twice as many new items. Hence, we could expect search in the $\mathrm{RG}+\underline{\mathrm{RGp}}$ condition to be more efficient than that in the $R G+G$ condition and also more efficient than that in the fullp baseline and the RG + RG preview conditions (for the same reason).

In Experiment 2, we repeated this procedure while employing preview displays that could be the same color as the anticipated target color $(\mathrm{R}+\underline{\mathrm{R}} \mathrm{Gp})$. Braithwaite et al. (2002) found that search for a target was slowed when it matched the color of the old distractors and the target's color was not anticipated. Here, we tested whether this effect would be overcome when the target's color could be anticipated. Thus, the main difference between Experiment 2 and Experiment 1 was that, here, the feature that was being actively prioritized was also the same as a feature common across the old items.

In Experiment 3, we replicated and extended the preview conditions of Experiments 1 and 2. In Experiment 3 , we systematically compared the effects of target color foreknowledge as a function of whether the previews contained letters in one or two colors. These manipulations allowed us to test the relative contributions from both the negative and the positive sets, respectively. If there were to be anticipated search only of new items in the target color, the homogeneity of the preview should not matter. However, if there were to be color-based grouping and inhibition of homogeneous previews, performance might suffer when the target shared this color (as compared with a baseline with a heterogeneous preview). In the foreknowledge conditions, this type of negative carryover might be pitted against anticipatory se- lection of the new target color. We will assess whether performance is some joint function of both effects.

In Experiment 4, we addressed an alternative account to one in which it is supposed that there is grouping and inhibition of old items. This alternative account holds that apparently negative color carryover effects are due to differences in the overall probability that the target will be a particular color (we thank Kyle Cave for this suggestion). We found that RTs were slowed to targets that were in the same color as the items in the preview display (e.g., red targets in the R + RG condition). In the new displays, the target had an equal probability of being a red or a green item. However, in terms of the overall number of items present in the final display, the target had a higher probability of being green (any green item was more likely to be a target than was any red item). It could be that RTs to red targets are slowed owing to this probability difference. We note here that probability alone is unlikely to be crucial, since in other studies we have used a full-set baseline where the color probabilities were matched to those in the critical preview condition here (e.g., approximately two thirds red, one third green). We have consistently failed to find differences in the detection of red and green targets in this case, even though such differences are striking in the preview condition (Braithwaite et al., 2002). Nevertheless, the probability account was directly tested in Experiment 4 by varying the probability that the target would be red or green in preview search (in the $\mathrm{R}+\mathrm{RG}$ condition). We will assess whether there was a negative carryover based on the color of the previews even when it was equally probable (although not certain) that the target had the same color as the preview stimuli.

\section{EXPERIMENT 1 Basic Effects of Foreknowledge}

\section{Method}

\section{Participants}

Sixteen participants (12 female; age range, 19-33 years; mean age, 23.4; all right-handed) from the University of Birmingham took part for a small payment. All had normal color vision and either normal or corrected-to-normal visual acuity.

\section{Stimuli and Apparatus}

All the stimuli and conditions were generated by a series of computer programs written in Turbo Pascal. The programs were run on 
a Pentium PC fitted with a 15 -in. super VGA monitor. The programs recorded all relevant keypress responses and RTs. This setup was used in all the subsequent experiments. The stimuli consisted of a subset of colored (either red or green) capital letters (with an approximate width of $5 \mathrm{~mm}$ and a height of $6 \mathrm{~mm}$ ) displayed on the plain black screen background. Average color values for both the red and the green items were determined during a pilot study that used a flicker color calibration test to ensure that these color groups were approximately isoluminant. The colored letter items were randomly assigned to an invisible 48 individual cell circular matrix consisting of three concentric circular ring grids. The distance from central fixation to the middle of the cells of the first ring measured approximately $19 \mathrm{~mm}$ (containing 8 cells), the distance to the second ring was $38 \mathrm{~mm}$ (containing 16 cells), and the distance to the third was $58 \mathrm{~mm}$ (containing 24 cells). Distractors consisted of the uppercase letters $\mathrm{H}, \mathrm{I}, \mathrm{V}$, and $\mathrm{X}$, and the target letter was either a Z or an N. Search displays were generated by randomly positioning each letter in the middle of individual matrix cells. Any distractor item could repeatedly occur in multiple numbers in any presentation, and their presence was based on a random function. The letter items occurred in two (red/green) randomly assigned colors that, averaged over trials, equaled a 50/50 heterogeneous color mix.

In the full-set baseline, there were two display sizes, with either 10 or 24 colored letter items. The half-set baseline consisted of 5 or 12 colored items, respectively. The preview conditions consisted of either 5 or 12 items occurring in the initial first display, with the same number of new items then appearing in the second search display. All the trials contained a target.

\section{Design and Procedure}

A $6 \times 2$ (condition $\times$ display size) within-subjects design was used. The six experimental conditions (summarized in Table 1) were as follows: (1) half (a single-color half-set baseline; all items were green); (2) full (a mixed-color [red + green] full-set baseline); (3) fullp (a full-set mixed-color condition with prior foreknowledge of the target's color); (4) RG $+\mathrm{G}$ (a preview condition with all the first items red and green and all the second items green); (5) RG + RG (a preview condition with both displays containing mixed red and green items); and (6) $R G+\underline{R} G p$ (an RG + RG preview condition with foreknowledge of the target's color). Each condition was run as a separate block of 80 trials (40 per display size). Trials within blocks were fully randomized across display sizes, and block order was randomized across participants. A general block of practice trials was completed at the beginning of the experiment. None of these practice trials was included in the analysis.

Each trial began with the presentation of a plain white fixation cross; this remained visible until the end of each trial. For the baseline conditions, after $1,000 \mathrm{msec}$ from fixation onset, the search display was presented and remained visible until a response key was pressed or a time-out period of $10,000 \mathrm{msec}$ had elapsed. This procedure was repeated for each trial for the duration of the experimental block. There was a 1,000-msec delay between individual trials in all the conditions.

In the preview conditions, each trial again began with the presentation of a central fixation cross. After 1,000 msec had elapsed, an initial set of distractor items was presented. These items were always irrelevant and had to be ignored irrespective of their color. The preview letters remained on the screen until the end of each trial. After a further period of 1,000 msec, the second set of search items, containing the target, was added to the display. In the baseline conditions, the participants were asked to search the displays as soon as the letters appeared. In the preview conditions, the participants were instructed to remain fixated and not to initiate search until the arrival of the second display. RTs were measured from the onset of the second display.

In the full-set baseline and the RG $+\mathrm{RG}$ preview conditions, the target could be red or green $50 \%$ of the time, so color provided no useful cue for search. The participants were instructed not to rely on color, since this was irrelevant to the task. In the $\mathrm{RG}+\mathrm{G}$ condition, the second array, including the target, was always green. In

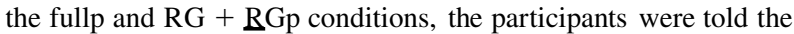
color of the target at the start of the relevant block of trials. For the foreknowledge conditions, the target color chosen was counterbalanced across participants. The participants were asked to search as fast, yet as accurately, as they could for all the conditions. The experiment lasted approximately $45 \mathrm{~min}$.

\section{Results}

The RT data were trimmed for outliers by removing RTs \pm 2.5 standard deviations from a particular mean in that condition and any response faster than $200 \mathrm{msec}$. Incorrect target responses were also removed. This procedure was used in all the subsequent experiments. The mean correct RTs were initially analyzed in a $6 \times 2$ (condition $\times$ display size) within-subjects analysis of variance (ANOVA). This revealed significant main effects of condition $[F(5,75)=41.773, p<.001]$ and display size $[F(1,15)=113.471, p<.001]$. The condition $\times$ display size interaction was also significant $[F(5,75)=$ 17.870, $p<.001$; see Figure 1].

This interaction was broken down to highlight the main comparisons across the conditions. First, we assessed the effects of color foreknowledge in the preview conditions by comparing effects of foreknowledge when Set 2 was mixed $(R G+\underline{R} G p$ vs. $R G+R G)$ and how this foreknowledge condition compared with performance when the second set of items was one color $(R G+\underline{R} G p$ vs. $R G+G)$. Subsequently, we evaluated performance in the preview conditions relative to each baseline. Comparisons with the half-set baseline tested whether only the new items were searched in the preview conditions. We tested whether having foreknowledge of the target's color was more of an advantage in preview search than in the full-set baseline condition ( $R G+\underline{R} G p$ vs. fullp) and whether any advantage was due to the preview alone $(\mathrm{RG}+\mathrm{RG}$ vs. fullp). We also evaluated whether there was any effect of foreknowledge in the full-set baseline condition itself (full vs. fullp). Finally, we evaluated (1) whether foreknowledge of the target's color in the full-set baseline condition brought performance down to the level of a half-set baseline condition (fullp vs. half) and (2) whether there was a standard preview effect, relative to the full-set baseline condition, even in the least efficient preview condition ( $R G+R G$ vs. full).

\section{Effects of Color Foreknowledge in Preview Conditions}

RG $+\underline{\text { RGp versus }} \mathbf{R G}+\mathbf{R G}$. The main effects of both condition and display size were significant $[F(1,15)=$ $39.895, p<.001$, and $F(1,15)=82.587, p<.001$, respectively]. The condition $\times$ display size interaction was also significant $[F(1,15)=28.879, p<.001]$. Providing target color knowledge in the RG $+\mathrm{RG}$ condition significantly improved search efficiency; the effect of display size was less in the $\mathrm{RG}+\underline{\mathrm{R} G p}$ condition than in the $\mathrm{RG}+\mathrm{RG}$ condition. 


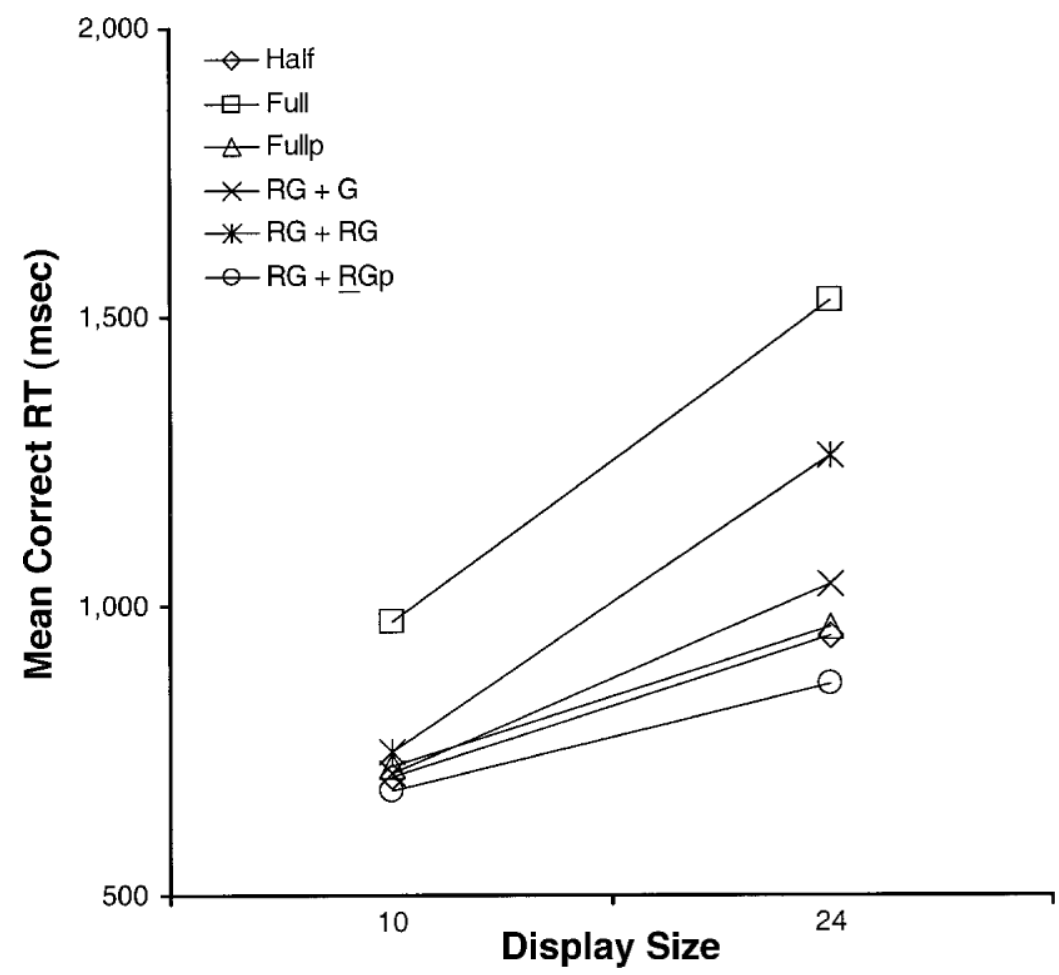

Figure 1. Mean correct reaction time (RT) for all conditions expressed across display size for Experiment 1. The conditions were half (half-set baseline), full (full-set baseline), fullp (full-set with prior target color knowledge), RG + G (preview condition, single-color second set), RG + RG (preview condition, mixed-color second set), and RG + RGp (preview condition, mixed-color second set with prior target color knowledge).

$\mathbf{R G}+\underline{\mathbf{R G p}}$ versus $\mathbf{R G}+\mathbf{G}$. The main effects of condition and of display size were significant $[F(1,15)=$ $12.268, p<.01$, and $F(1,15)=63.101, p<.001$, respectively]. The condition $\times$ display size interaction was also significant $[F(1,15)=8.702, p<.05]$. RTs in the $\mathrm{RG}+\underline{\mathrm{R}} \mathrm{Gp}$ condition showed a smaller increase across the two display sizes than did those in the $\mathrm{RG}+\mathrm{G}$ condition (even though the participants had color foreknowledge in both cases).

\section{Half-Set Versus Preview Effects}

Half versus RG $+\mathbf{G}$. The main effect of condition failed to reach significance $[F(1,15)=2.854, p=.112]$. The main effect of display size was significant $[F(1,15)=$ $58.688, p<.001]$. The condition $\times$ display size interaction failed to reach significance $[F(1,15)=2.598, p=$ $.128]$. Search performance in the $\mathrm{RG}+\mathrm{G}$ condition was as efficient as that in the half-set baseline.

Half versus RG + RG. There were significant main effects of condition $[F(1,15)=28.661, p<.001]$ and display size $[F(1,15)=66.422, p<.001]$. The condition $X$ display size interaction was also significant $[F(1,15)=25.502, p<.001]$. RTs in the RG + RG condition increased more with display size than did those in the half-set baseline condition.
Half versus RG $+\underline{\mathbf{R G}}$. The main effect of condition was significant $[F(1,15)=7.338, p<.05]$, as was the main effect of display size $[F(1,15)=63.950, p<$ $.001]$. The condition $\times$ display size interaction was not significant $[F(1,15)=3.015, p=.103]$. RTs in the $\mathrm{RG}+\mathrm{RG}$ condition were longer than those in the half-set baseline condition, the $R G+G$ condition was equivalent to this baseline, and RTs in the RG $+\underline{\mathrm{R} G p}$ condition were shorter than those the half-set baseline condition.

\section{Full-Set Comparisons}

Fullp versus full. The main effects both of condition $[F(1,15)=53.181, p<.001]$ and of display size $[F(1,15)=115.376, p<.001]$ were significant. The condition $\times$ display size interaction was also significant $[F(1,15)=37.728, p<.001]$. Search was more efficient in the full-set baseline condition when the participants had foreknowledge of the target's color.

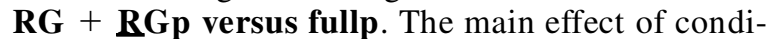
tion was significant $[F(1,15)=7.246, p<.05]$. The main effect of display size was significant $[F(1,15)=$ $120.276, p<.001]$. The condition $\times$ display size interaction was not significant $[F(1,15)=4.010, p=.064]$. There was an overall mean advantage of $72 \mathrm{msec}$ for the $R G+\underline{R G p}$ condition. 
RG + RG versus fullp. The main effects of both condition and of display size were significant $[F(1,15)=$ $16.276, p<.01$, and $F(1,15)=81.804, p<.001$, respectively]. The condition $\times$ display size interaction was also significant $[F(1,15)=26.257, p<.001]$. RTs in the fullp condition were, on average, $160 \mathrm{msec}$ shorter than those in the RG + RG condition.

\section{Half Set Versus Full Set With Prior Knowledge}

Fullp versus half. The main effect of condition failed to reach significance $[F(1,15)=0.588, p=.466]$. The main effect of display size was significant $[F(1,15)=$ $70.200, p<.001]$. The condition $\times$ display size interaction was not significant $[F(1,15)=0.013, p=.911]$. Foreknowledge of target color reduced full-set search RTs to the level consistent with a half-set search.

\section{Full Versus RG 1 RG}

The least efficient preview condition $(R G+R G)$ was compared with the full-set baseline condition for a measure of search improvement. The main effects both of condition and of display size were significant $[F(1,15)=$ $47.249, p<.001$, and $F(1,15)=94.343, p<.001$, respectively]. The condition $\times$ display size interaction was not significant $[F(1,15)=0.506, p=.488]$. There was an overall preview advantage for RTs ( $246 \mathrm{msec})$.

\section{Errors}

Errors followed the general pattern of the RTs (see Figure 2). These data were not analyzed further. With the trimmed data included, the overall error rate was low at $4.18 \%$. There were no signs of a speed-accuracy tradeoff.

\section{Discussion}

Performance in all the preview conditions benefited relative to the full-set baseline condition (and in some cases, relative to the half-set baseline; see below). Consistent with prior findings, preview search was much more efficient in the RG $+\mathrm{G}$ condition than in the $\mathrm{RG}+$ $R G$ condition (e.g., there were smaller effects of display size in the RG + G condition; see also Braithwaite et al., 2002). Preview search was facilitated when the new items had a common color, relative to when they had two colors. This result is consistent with the participant's adopting an anticipatory set for new items of a predesignated color, when Display 2 contained items of just one color.

Although there was an improvement in RTs for the $\mathrm{RG}+\mathrm{RG}$ condition relative to the full-set baseline condition, this was mainly in terms of overall RT differences between the conditions. This may well have been due to the following three factors: (1) Old items could not be grouped and inhibited on the basis of a shared color; (2) the target shared its color with half the old items; and (3) a target set for color could not be initiated. The combined net result of these factors may mean that some old items did come to be searched. The intercept advantage, then, may arise because search may be initiated quickly to new items but carryover effects of color inhibition and/or grouping lead to new items being treated equiva-

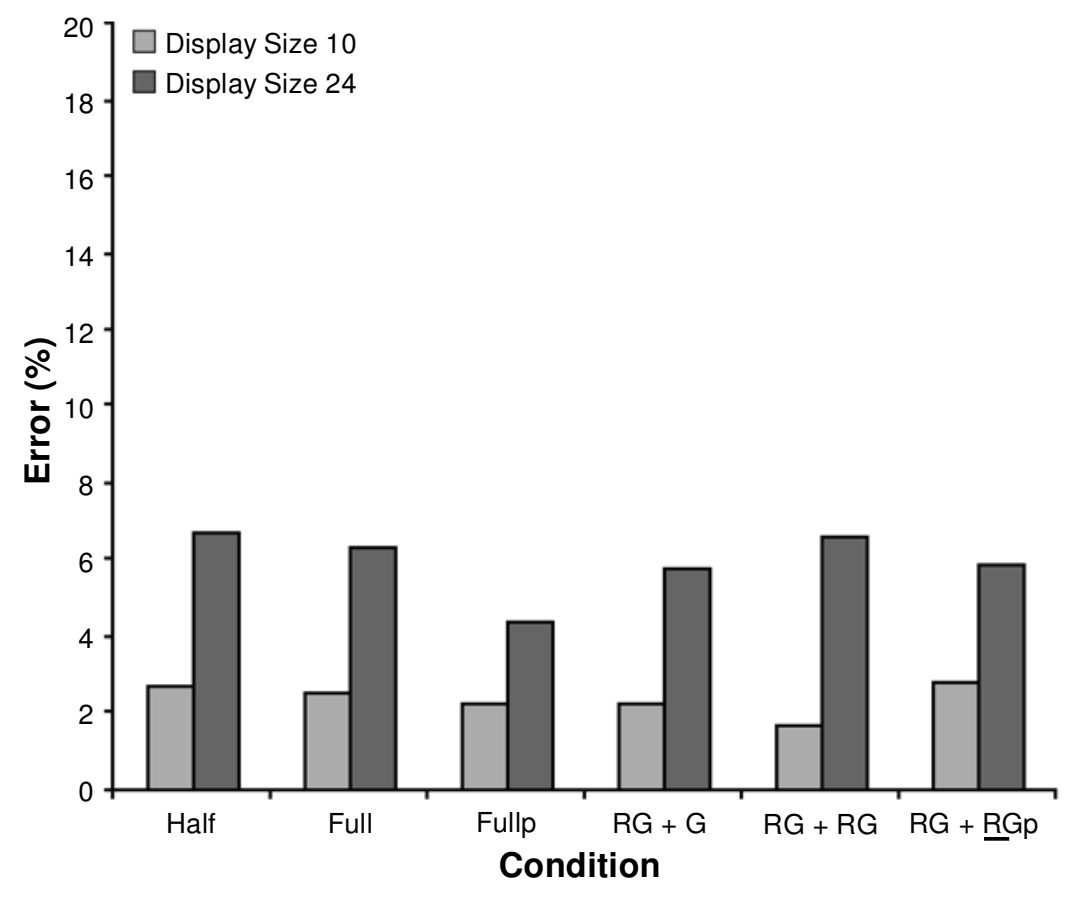

Figure 2. Errors (expressed as percentage) for each condition and display size in Experiment 1. 
lently to those in the old set. Interestingly, performance in this preview condition ( $R G+R G)$ was worse than that in the full-set baseline condition when foreknowledge of the target color was provided (fullp). This result is noteworthy because it cannot be accounted for in terms of attentional capture by new stimuli. In the fullp condition, search should have proceeded through just half the items (at most), with, on average, about $25 \%$ of the items being sampled before the target was found. If there was attentional capture by the new stimuli in the $\mathrm{RG}+\mathrm{RG}$ condition, then again, just half the items should have been searched, with the target being found after $25 \%$ had been sampled. That is, search slopes should have been identical in the two conditions, with the guidance of the search process being based on the known target color in one case (fullp) and on temporal onset in the other $(R G+R G)$. In contrast, the slopes on the search function for the preview $R G+R G$ condition were approximately more than double those in the fullp condition. As well as countering a new-object capture account, this finding also emphasizes that search in the $\mathrm{RG}+\mathrm{RG}$ condition was not optimal, so that old items had some impact on search.

When the participants were given prior knowledge of what color group to expect the target to occur in (in new mixed-color displays), search for those targets was greatly improved. For the full-set baseline condition, foreknowledge of the target's color (e.g., the fullp condition) improved search to a level as efficient as that in the half-set baseline condition. Note that there was the same number of items in the designated target color in the fullp condition as in the half-set baseline condition, so the equality of performance could be expected if there was efficient prioritization of search of items in the target's color.

In addition to the effects of color foreknowledge in the full-set baseline condition (fullp), there were also effects of foreknowledge of the target color in the preview condition. Performance for the RG $+\underline{R G p}$ condition was significantly (and substantially) improved, when compared with the $R G+R G$ condition (generating smaller effects of display size on search). Furthermore, RTs were shorter in the $\mathrm{RG}+\underline{\mathrm{R}} \mathrm{gp}$ preview condition than in the $\mathrm{RG}+\mathrm{G}$ preview and the fullp baseline conditions. This is consistent with search's being restricted, not just to a color-defined group (e.g., the red items), but to the new red items. The RG $+\underline{\mathrm{R} G p}$ condition was advantaged relative to the $R G+G$ condition because there were fewer new items in the target color in the former case (note that the half-set baseline condition was also equated to the $\mathrm{RG}+\mathrm{G}$ condition despite the fact that there were more items in the target color overall in the $R G+G$ condition; this is also consistent with the participants' configuring their search to just the new items in this $R G+G$ condition). Clearly, there are large advantages to be had in preview presentations from knowing the target's color. This advantage again improved RTs overall and led to re- duced effects of the display size on performance. These target foreknowledge advantages in preview search reflect the combined effects of color and time.

The data suggest that participants can set themselves to search just a predefined new-color subset. For the baseline conditions, this may mean searching just the relevant color group once presented (fullp). For the preview condition, participants can restrict search to just the new relevant items $(\mathrm{RG}+\underline{\mathrm{R}} \mathrm{Gp})$. In both cases, the relevant and anticipated feature dimension is prioritized for search. This proposal is in line with many studies outlining a role for top-down modulation and anticipation in search and selection (e.g., Bacon \& Egeth, 1994, 1997; Folk \& Remington, 1996; Folk et al., 1992; Folk et al. 1994; Moore \& Egeth, 1998). There seems to be little impact from the old items when observers can explicitly prioritize the new relevant feature dimension. Apparently, when a valid anticipatory set can be initiated, there is minimal effect of either inhibition and/or grouping from the old previews to the new items.

However, this last proposal may oversimplify the situation. In the preview conditions in Experiment 1, the old items were always mixed in color (e.g., $R G+G$ vs. $\mathrm{RG}+\mathrm{RG})$. This means that inhibition by common color may not be optimally employed to minimize the impact of the old items on search. Indeed, it may be easier to initiate the anticipatory set for a specific target color if that color is not heavily represented (and inhibited) across the old items. Effects that are due to anticipation of the target color may be maximized under these conditions.

In Experiment 2, we tested these proposals. Here, we asked whether foreknowledge of the target color could be effective when this color was the same as the color of all the old items in the preview. Braithwaite et al. (2002) reported that search was difficult under preview conditions when (1) participants had no foreknowledge of the target color and (2) the target in the new set was the same color as a set of preview items that had a common color (e.g., in a preview $\mathrm{R}+\mathrm{RG}$ condition with red targets). We replicated this result here. Note that, in this critical preview condition, the target had a majority color overall, relative to all the items in the display (taking old and new items together, two thirds of the items had the target's color). This raises the question of whether the slowing of search in the $\mathrm{R}+\mathrm{RG}$ condition was due to the red target's appearing in the majority color, rather than to any negative carryover from the preview. However, this is unlikely. In control studies, we have run full-set conditions in which majority-minority differences were used that were more extreme than the $66 \%-33 \%$ color contrast found in the $\mathrm{R}+\mathrm{RG}$ condition (e.g., a $75 \%-25 \%$ difference and even an $83 \%-17 \%$ difference). Even under these more extreme conditions, we have failed to find significant effects of the color ratio of the distractors (Braithwaite et al., 2002, in press). ${ }^{3}$ Therefore, the significant costs in the preview condition (in $\mathrm{R}+\mathrm{RG}$ for red targets) suggests some form of inhibitory carryover from the old 
red items (cf. Watson \& Humphreys, 1998). This can particularly penalize search for new red items when participants do not have advance knowledge of the target color.

In the new condition here, the participants had advance knowledge of the target's color (e.g., in the preview condition, $R+\underline{R} G p$ ). If the participants could prioritize search to just the new items in the target's color, performance should have been more efficient than that in a full-set baseline, where advance knowledge of a target's color was also given (fullp). In the preview condition, there were approximately half the number of new items in the target's color than was the case for the fullset baseline condition.

\section{EXPERIMENT 2 Foreknowledge for Ignored Colors}

\section{Method}

\section{Participants}

Eighteen participants (14 female; age range, 18-29 years; mean age, 23.7; two were left-handed) from the University of Birmingham took part for a small payment. All had normal or corrected-tonormal vision.

\section{Stimuli and Apparatus}

All the stimuli were identical to the two color (red/green) arrays used in Experiment 1. Again, target color was prespecified for the relevant conditions.

\section{Design and Procedure}

The design and procedure were very similar to those in Experiment 1 . A $6 \times 2$ within-subjects design was used. The conditions are summarized in Table 2 and were as follows: (1) half (a half-set baseline, all green); (2) full (a full-set mixed-color red and green baseline); (3) fullp (a full-set baseline with prior target color knowledge); (4) $R+G$ (a preview condition with all first items red, all second items green); (5) $\mathrm{R}+\mathrm{RG}$ (a preview condition with all first items red and all second items mixed red and green); and (6) $\mathrm{R}+\underline{\mathrm{R} G p}$ (a preview condition with all first items red and all second items mixed red and green, but with observers being given prior knowledge of the target color group; here, this was always red, the color of the old items).

For the standard conditions, the target color was 50\% green, $50 \%$ red (randomly determined). In the color foreknowledge conditions, the participants were told the target's color at the start of the relevant block of trials. A target ( $\mathrm{N}$ or $\mathrm{Z}$ ) was always present, and in the color foreknowledge conditions, the target was always the designated color. For the fullp condition, the target color was counterbalanced across participants. For the $\mathrm{R}+\underline{\mathrm{R}} \mathrm{Gp}$ condition, the target was always the same as the color of the letter set being ignored (red for half the participants, green for the others). The rest of the procedure was the same as that in Experiment 1.

\section{Results}

The mean correct RTs for each condition are plotted as a function of the display size in Figure 3 . These data were subjected to an overall $6 \times 2$ (condition $\times$ display size) within-subjects ANOVA, which revealed significant main effects of both condition $[F(5,85)=25.305, p<$ $.001]$ and display size $[F(1,17)=111.514, p<.001]$. The condition $\times$ display size interaction was also significant $[F(5,85)=18.403, p<.001]$. The results were broken down in a manner similar to that in Experiment 1 (see Figure 3). In the following analyses, we decomposed this interaction by focusing on the main comparisons of interest. We note that the standard pattern of preview search was apparent in the experiment. Performance in a preview condition with all red old and all green new items was equivalent to that in the half-set baseline condition, and performance in both of these conditions better than that in the full-set baseline condition.

\section{Preview Effects}

To assess whether there was a negative color carryover/ grouping effect, performance in the $\mathrm{R}+\mathrm{RG}$ preview condition was broken down according to the target's color, and separate comparisons were made relative to a standard preview, with red Set 1 and green Set 2 stimuli. Search may be particularly difficult when the target has the same color as the preview (red targets in the R + RG condition; Braithwaite et al., 2002).

Green targets $(\mathbf{R}+\mathbf{R G})$ versus $\mathbf{R}+\mathbf{G}$. The main effect of condition was not significant $[F(1,17)=1.579$, $p=.226]$. The main effect of display size was significant $[F(1,17)=108.423, p<.001]$. The condition $\times$ display size interaction was not significant $[F(1,17)=$ $1.784, p=.199$ ]. Despite only half the number of items' sharing the target's color, RTs for green minority targets showed that search in the $\mathrm{R}+\mathrm{RG}$ condition was only as efficient as was search in the $R+G$ condition.

Red targets $(\mathbf{R}+\mathbf{R G})$ versus $\mathbf{R}+\mathbf{G}$. The main effects of both condition and display size were significant $[F(1,17)=13.203, p<.01$, and $F(1,17)=66.578, p<$ $.001]$. The condition $\times$ display size interaction was also significant $[F(1,17)=20.301, p<.001]$. Although search

Table 2

The Experimental Conditions, Color Combinations, and Target Colors for Experiment 2

\begin{tabular}{lcccl}
\hline Condition & Preview Display & Search Display & Foreknowledge & Target Color \\
\hline Half set & - & $\mathrm{G}$ & $\checkmark$ & green \\
Full set & - & $\mathrm{RG}$ & $\times$ & either $(50 \%)$ \\
Fullp & - & $\mathrm{RG}$ & $\checkmark$ & red (or green)* \\
$\mathrm{R}+\mathrm{G}$ & $\mathrm{R}$ & $\mathrm{G}$ & $\checkmark$ & green \\
$\mathrm{R}+\mathrm{RG}$ & $\mathrm{R}$ & $\mathrm{RG}$ & $\times$ & either $(50 \%)$ \\
$\mathrm{R}+$ RGp & $\mathrm{R}$ & $\mathrm{RG}$ & $\checkmark$ & red (or green $)^{*}$ \\
\hline
\end{tabular}

Note-The notation in the foreknowledge column refers to whether, in that individual condition, the observers were provided with foreknowledge (denoted by a $\checkmark$ ) or were not provided with foreknowledge $($ denoted by $\mathrm{a} \times)$. * Counterbalanced across participants. 


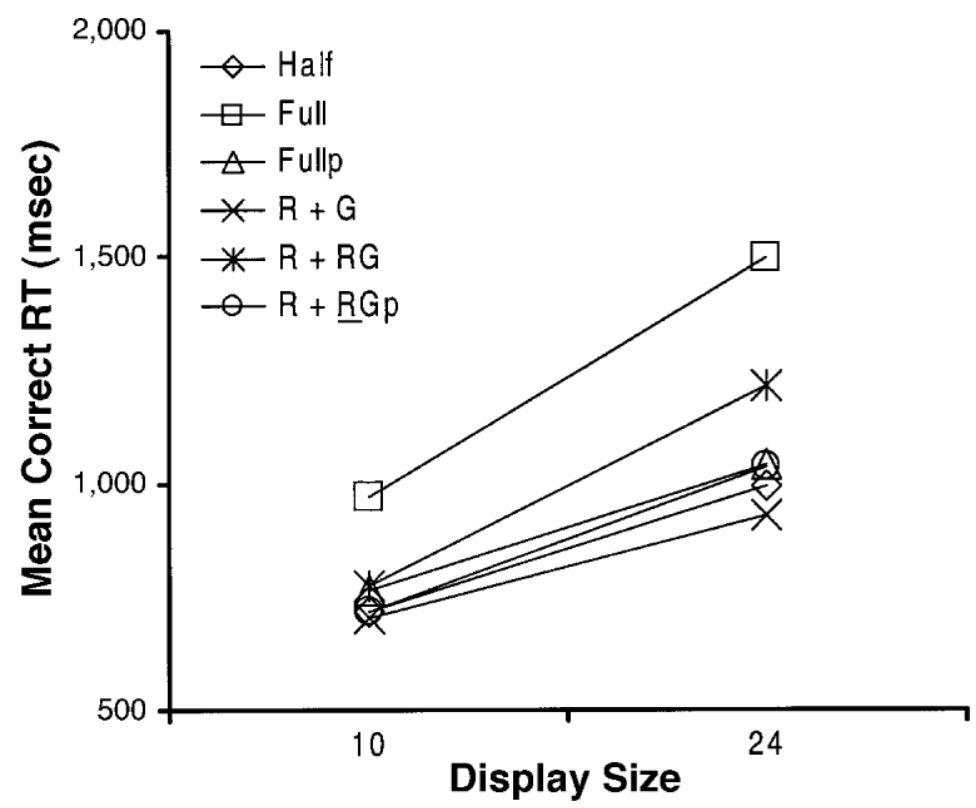

Figure 3. Mean correct reaction time (RT) for all conditions expressed across display size for Experiment 2. The conditions were half (half-set baseline), full (full-set baseline), fullp (full-set with prior target color knowledge), $\mathbf{R}+\mathbf{G}$ (preview condition, single-color first and second sets), $R+R G$ (preview condition mixed-color second set, single-color first set), and $\mathbf{R}+\underline{\mathbf{R G p}}$ (preview condition, single-color first set, mixed-color second set with prior target color knowledge).

was based on twice as many new items in the target color, $\mathrm{RT}$ in the $\mathrm{R}+\mathrm{G}$ condition were considerably shorter (on average, by $303 \mathrm{msec}$ ) and more efficient than those for red targets in the $\mathrm{R}+\mathrm{RG}$ condition. This is consistent with a negative effect of color carryover from preview displays.

\section{Effects of Color Foreknowledge}

We first will compare overall search performance between the $\mathrm{R}+\mathrm{G}$ and the $\mathrm{R}+\mathrm{RG}$ preview conditions, and between the $\mathrm{R}+\mathrm{G}$ and $\mathrm{R}+\underline{\mathrm{R}} \mathrm{Gp}$ preview conditions. We will then assess the effects of color foreknowledge in the preview and full-set conditions by comparing each foreknowledge condition with the equivalent no-foreknowledge condition. In the preview condition, the no-foreknowledge baseline was broken down according to whether the target was red or green.

$\mathbf{R}+\mathbf{G}$ versus $\mathbf{R}+\mathbf{R G}$. The main effects of both condition $[F(1,17)=27.523, p<.001]$ and display size $[F(1,17)=87.971, p<.001]$ were significant. The condition $\times$ display size interaction was also significant $[F(1,17)=28.572, p<.001]$. Search performance in the $\mathrm{R}+\mathrm{RG}$ condition was slower and less efficient than that in the $\mathrm{R}+\mathrm{G}$ condition.

$\mathbf{R}+\mathbf{G}$ versus $\mathbf{R}+\underline{\mathbf{R}} \mathbf{G p}$. The main effects of both condition $[F(1,17)=5.801, p<.05]$ and display size $[F(1,17)=138.377, p<.001]$ were significant. The condition $\times$ display size interaction was also significant $[F(1,17)=5.433, p<.05]$. RTs for the $\mathrm{R}+\underline{\mathrm{R} G p}$ condition were longer and less efficient than those for the $\mathrm{R}+$ $\mathrm{G}$ condition, despite the fact that search in the $\mathrm{R}+\underline{\mathrm{R}} \mathrm{Gp}$ condition should be based on approximately half the number of items, relative to the $\mathrm{R}+\mathrm{G}$ condition.

Red targets $(\mathbf{R}+\underline{\mathbf{R}} \mathbf{G p})$ versus green targets $(\mathbf{R}+$ RG). Only the main effect of display size was significant $[F(1,17)=108.367, p<.001]$. Neither the main effect of target color $[F(1,17)=0.315, p=.582]$ nor the target color $\times$ display size interaction $[F(1,17)=0.763, p=$ $.395]$ was significant. There was no advantage for the foreknowledge condition, relative to a baseline condition in which the targets differed in color from the old distractors.

Red targets $(\mathbf{R}+\underline{\mathbf{R}} \mathbf{G p})$ versus red targets $(\mathbf{R}+$ RG). There were significant main effects of target color $[F(1,17)=15.253, p<.01]$ and display size $[F(1,17)=$ $63.505, p<.001]$. The target color $\times$ display size interaction was also significant $[F(1,17)=15.433, p<.01]$. Search was more efficient when the participants had foreknowledge of the target's color (in the $\mathrm{R}+\underline{\mathrm{R} G p}$ condition vs. the $\mathrm{R}+\mathrm{RG}$ condition).

Full versus fullp. There were significant main effects of condition and display size $[F(1,17)=32.878, p<$ .001 , and $F(1,17)=105.497, p<.001$, respectively]. The condition $\times$ display size interaction was also significant $[F(1,17)=34.499, p<.001]$. Providing the participants with color group knowledge improved search, on average, by $333 \mathrm{msec}$. This effect increased at the larger display size.

To assess whether target color foreknowledge led to any advantage for the preview, relative to the full-set baseline (with foreknowledge), we also compared the $\mathrm{R}+\underline{\mathrm{R} G p}$ and fullp conditions. 
$\mathbf{R}+\underline{\mathbf{R} G p}$ versus fullp. The main effect of condition was not significant $[F(1,17)=1.688, p=.211]$. The main effect of display size was significant $[F(1,17)=$ $90.570, p<.001]$. The condition $\times$ display size interaction was not significant $[F(1,17)=3.106, p=.096]$. There was no advantage for the preview, relative to the full-set baseline, when the participants had foreknowledge of the target's color.

\section{Separating Performance According to the Color of the Target in the Preview Condition}

The critical preview condition $(\mathrm{R}+\mathrm{RG})$ was compared against the half-set baseline condition.

Green targets ( $R+\mathbf{R G})$ versus half. The main effect of condition was not significant $[F(1,17)=0.041, p=$ $.841]$. The main effect of display size was significant $[F(1,17)=93.520, p<.001]$. The condition $\times$ display size interaction failed to reach significance $[F(1,17)=$ $0.001, p=.974]$. Despite there being more green items in the half-set baseline condition, search RTs were not more efficient in the preview condition ( $+R G)$.

Red targets ( $R+\mathbf{R G )}$ versus half. The main effects of both condition and display size were significant $[F(1,17)=11.700, p<.01$ and $[F(1,17)=59.380, p<$ .001 , respectively]. The condition $\times$ display size interaction was also significant $[F(1,17)=17.796, p<.01]$. $\mathrm{RTs}$ to red targets in the $\mathrm{R}+\mathrm{RG}$ condition were greatly slowed (on average, by $263 \mathrm{msec}$ ) relative to the half-set baseline. This effect increased at the larger display size.

$\mathbf{R}+\underline{\mathbf{R} G p}$ versus half. The main effect of condition was not significant $[F(1,17)=0.303, p=.589]$, but the main effect of display size was $[F(1,17)=78.294, p<$
$.001]$. The condition $\times$ display size interaction was not significant $[F(1,17)=1.916, p=.184]$. With foreknowledge of the target color, search was as efficient in the $\mathrm{R}+\underline{\mathrm{R} G p}$ preview as in the half-set baseline condition (green only).

\section{Preview Versus Full-Set Baseline}

The most inefficient preview search condition (here, the $\mathrm{R}+\mathrm{RG}$ condition) was compared with the full-set baseline condition for a measure of search improvement. Main effects of both condition $[F(1,17)=23.822, p<$ $.001]$ and display size $[F(1,17)=97.295, p<.001]$ were significant. The condition $\times$ display size interaction was just significant $[F(1,17)=4.676, p<.05]$. The $\mathrm{R}+\mathrm{RG}$ condition showed a reliable preview benefit, as compared with the full-set baseline condition (on average, $239 \mathrm{msec}$ ).

\section{Errors}

The overall experimental error rate was low at $3.73 \%$. Errors generally followed the pattern of the RTs, and there was no indication of a speed-accuracy tradeoff (see Figure 4).

\section{Discussion}

In all the preview conditions, there were substantial improvements in search, relative to the full-set baseline condition. The advantage for the $\mathrm{R}+\mathrm{RG}$ preview here could be due to the two colors' not having an even distribution in the full display (in the preview condition, whereas there was an even split in the baseline condition). However, the advantage held even for targets in the majority color (red), which may be expected to be searched after the minority color set (Bacon \& Egeth, 1997; Egeth

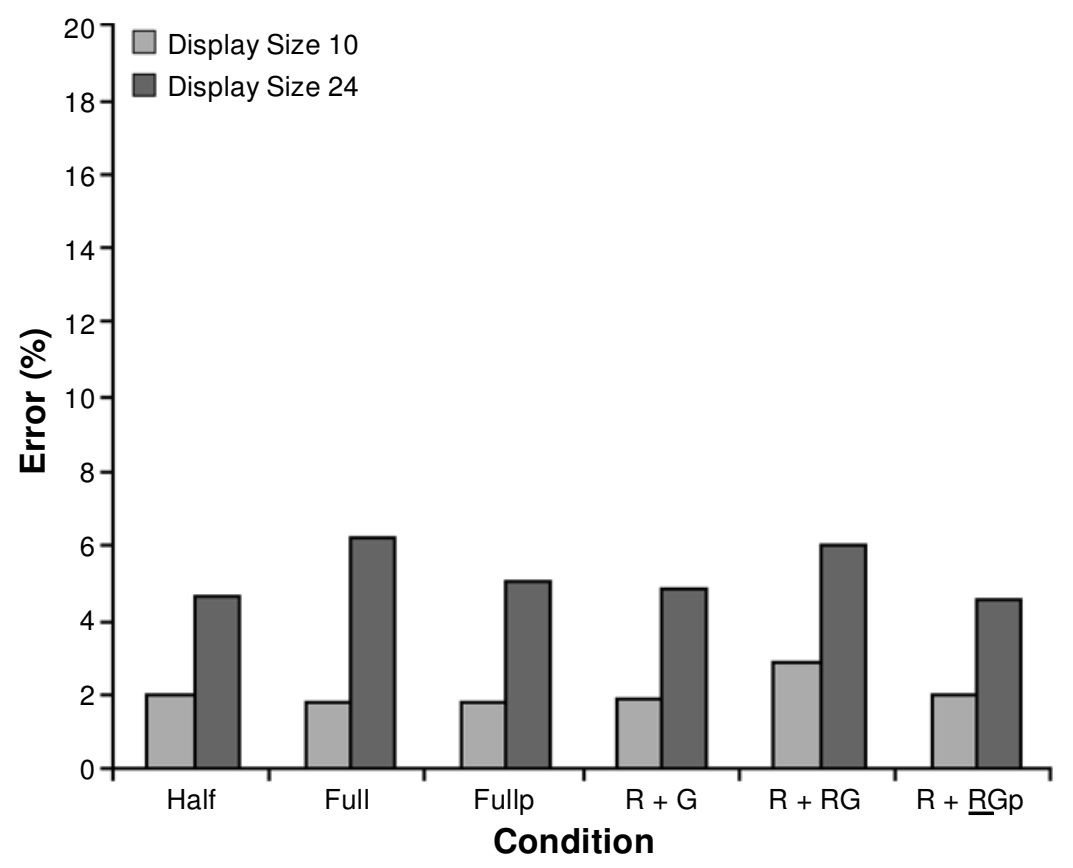

Figure 4. Errors (expressed as percentage) in each condition and display size in Experiment 2. 
et al., 1984; Kaptein et al., 1995; Moore \& Egeth, 1998). Also, in other studies, we have failed to find effects of even more extreme ratios in full-set search. Hence, it seems that color segregation alone was not sufficient and that the temporal separation between the distractors facilitated selection of the new items. Nevertheless, performance in the $\mathrm{R}+\mathrm{G}$ preview was quicker and more efficient (in terms of slope and overall RT) than that in the $\mathrm{R}+\mathrm{RG}$ preview condition. We suggest that this is due, in part, to participants' adopting an anticipatory set for color in the $\mathrm{R}+\mathrm{G}$ condition that could not be initiated in the $\mathrm{R}+\mathrm{RG}$ condition (in which the second search set was mixed in color and the target color was not known).

Consistent with Experiment 1, Experiment 2 also showed large search benefits when target color knowledge was provided, in comparison with when the target's color was uncertain. This held for both the baseline (full vs. fullp) and the preview presentation conditions. However, unlike in Experiment 1, there was no additional benefit for the preview condition with foreknowledge $(\mathrm{R}+\underline{\mathrm{R} G p}=$ fullp $)$. Also in contrast with Experiment 1 , there was no advantage for this preview condition, as compared with the half-set baseline condition. This is of interest because there were fewer new items in the designated target color in the preview condition $(\mathrm{R}+\underline{\mathrm{R}} \mathrm{Gp})$ than in either the full-set baseline condition with foreknowledge (fullp) or the half-set baseline condition (e.g., where all items were green). If search could have been selectively set to just the new items in the expected target color, performance should have been more efficient in the preview condition with foreknowledge than in either of the above baseline conditions. It was not.

Furthermore, search in the $\mathrm{R}+\underline{\mathrm{R}} \mathrm{Gp}$ preview condition was slower overall (overall RT) and less efficient (in terms of slope) than that in the $\mathrm{R}+\mathrm{G}$ preview condition. In the $R+G$ preview condition, the participants again had foreknowledge of the target's color, but there were more new items in that color than in the $\mathrm{R}+\underline{\mathrm{R} G p}$ condition (indeed, on average, twice as many). On the basis of selective search of just the new items in the target color set, we would expect the opposite result (e.g., R + $\underline{\mathrm{R}} \mathrm{Gp}<\mathrm{R}+\mathrm{G})$. These results highlight the fact that although the participants used their advanced knowledge of the target's color in the preview condition $(R+\underline{R} G p)$, this did not prevent some impact of the old items that here shared the target's color. This runs counter to an account of the preview benefit cast purely in terms of onset capture by the second display (Donk \& Theeuwes, 2001) and to accounts in which it is assumed that performance is influenced only by relevant target feature prioritization (e.g., anticipation of the target's features; Bacon \& Egeth, 1997; Egeth et al., 1984; Kaptein et al., 1995; Moore \& Egeth, 1998).

The data are consistent with prior studies of preview search that have demonstrated carryover effects based on featural similarity between Displays 1 and 2 (e.g., Braithwaite et al., 2002; Gibson \& Jiang, 2001; Olivers $\&$ Humphreys, 2002). If participants were to adopt an inhibitory set toward Display 1, inhibition might spread to at least some new items sharing the properties of the inhibited (old) stimuli. This carryover effect may be particularly pronounced when all the items in Display 1 have a common color and, so, may be inhibited on the basis of this shared property. Therefore, we propose that, here, grouping and inhibition combine over time to produce strong carryover effects in search (see the General Discussion section for more detail about the relationship between grouping and inhibition).

Experiment 3 was designed to provide a full test of this last proposal. To do this, we had the participants carry out search in the critical preview conditions from Experiments 1 and 2: $\mathrm{RG}+\mathrm{RG}, \mathrm{RG}+\underline{\mathrm{R} G p}$ (from Experiment 1), and $\mathrm{R}+\mathrm{RG}, \mathrm{R}+\underline{\mathrm{R} G p}$ (with a red target, from Experiment 2). In all of these preview conditions, the second search displays were the same (although the final overall displays, once both sets were present, were in some cases different). If, given color foreknowledge, the participants could prioritize new items in the target's color, search should have been equally efficient in the $\mathrm{RG}+\underline{\mathrm{R} G p}$ and $\mathrm{R}+\underline{\mathrm{R}} \mathrm{Gp}$ conditions. However, if there was color-based inhibition of the old items when they had a common color and if this carried over from Display 1 to Display 2, performance might have been less

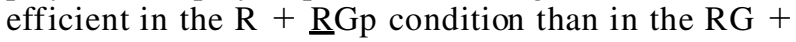
$\mathrm{RGp}$ condition. In addition to these critical preview conditions, two baseline preview conditions were added: RG $+\mathrm{G}$ and $\mathrm{G}+\underline{\mathrm{R}} \mathrm{Gp}$. The $\mathrm{RG}+\mathrm{G}$ condition provided a test where all the new items were in a known target color. If there was prioritized search of the known target color in the $\mathrm{RG}+\underline{\mathrm{R} G p}$ and $\mathrm{R}+\underline{\mathrm{R}} \mathrm{Gp}$ conditions, these conditions should have been more efficient than the RG + $\mathrm{G}$ baseline; there were more new items in the target's color in the baseline preview condition.

The $\mathrm{G}+\underline{\mathrm{R}} \mathrm{Gp}$ condition was new to this experiment and represented the case in which the target color was known but was in the minority color set in the full display (e.g., with a red target, in this instance). Search for a target in a known color in a minority set should have been particularly effective in this preview condition. This condition might also have benefitted from color-based inhibition of the old distractor set (since this set of items had a single color). This can be assessed by comparing performance in this condition with that in the RG $+\underline{R G p}$ condition. Again, the second displays were the same in this comparison (note that, in the final overall display, there were more green items in the $\mathrm{G}+\underline{\mathrm{R} G p}$ condition). If there was just capture by the new items in the expected target color, performance should not have differed in these conditions. However, if there was color-based inhibition of old green distractors that transferred to the new items, search may have been more efficient in the $\mathrm{G}+\underline{\mathrm{R}} \mathrm{Gp}$ condition than in the $R G+\underline{R G p}$ condition. Whether foreknowledge of the target's color aids search over and above the target's being in a minority set overall can be assessed by comparing search with the $\mathrm{R}+\mathrm{RG}$ preview (with no foreknowledge of the target color) when the target was (again) in the minority color (green, in this case). The full list of preview conditions is given in Table 3 . 


\section{EXPERIMENT 3 \\ Evidence for Grouping and Inhibition}

\section{Method}

\section{Participants}

Seventeen participants from the University of Birmingham (12 female; age range, 19-32 years; mean age, 25 years; 16 were righthanded) took part for a small payment. All reported that they had normal or corrected-to-normal vision.

\section{Stimuli and Apparatus}

All the stimuli and the apparatus were identical to the two-color (red/green) arrays used in the previous experiments. Again, target color was prespecified for the relevant conditions.

\section{Design and Procedure}

The design and procedure were similar to those in the previous experiments. A $6 \times 2$ (condition $\times$ display size) within-subjects design was used. However, here the half and full-set baseline conditions were dropped, and all the experimental conditions involved preview search. The conditions are summarized in Table 3 . The rest of the procedure was the same as that in the previously reported experiments.

\section{Results}

The mean correct RTs for each condition are plotted as a function of the display size in Figure 5. These data were entered into an overall $6 \times 2$ (condition $\times$ display size) within-subjects ANOVA. This revealed significant main effects of condition $[F(5,80)=23.487, p<.001]$ and display size $[F(1,16)=66.657, p<.001]$. The condition $\times$ display size interaction was also significant $[F(5,80)=13.070, p<.001]$. This overall interaction was broken down in a series of critical comparisons. First, we assessed the effects of target color knowledge in the preview conditions according to whether Set 1 displays had a single color or mixed colors. We then assessed the effects as a function of whether Set 2 displays had a single color or mixed colors. We subsequently compared each foreknowledge preview condition with a no-foreknowledge preview condition.

\section{Effect of Target Color Foreknowledge on Preview Search}

With a mixed-color Set 1: RG + RG versus RG + RGp. The main effects of both condition $[F(1,16)=$ $27.021, p<.001]$ and display size $[F(1,16)=42.888$, $p<.001]$ were significant, as was the condition $\times$ display size interaction $[F(1,16)=20.038, p<.001]$. RTs in the $\mathrm{RG}+\underline{\mathrm{R}} \mathrm{Gp}$ condition increased less than those in the $\mathrm{RG}+\mathrm{RG}$ condition, as the display size increased.

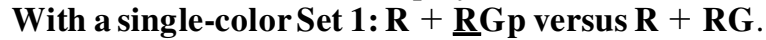
The main effect of condition was significant $[F(1,16)=$ $8.517, p<.05$ ], as was the main effect of display size $[F(1,16)=54.020, p<.001]$. There was also a reliable condition $\times$ display size interaction $[F(1,16)=5.451$, $p<.05]$. Again, there was a benefit from foreknowledge of the color of the target, particularly at the larger display size.

Comparison of the foreknowledge conditions: RG

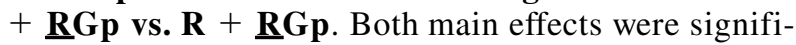
cant: condition $[F(1,16)=21.457, p<.001]$ and display size $[F(1,16)=42.582, p<.001]$. The condition $\times$ display size interaction was also significant $[F(1,16)=$ $13.541, p<.01]$. The advantage of foreknowledge was greater when Set 1 had mixed colors (in the $R G+\underline{R} G p$ condition) than when Set 1 had a single color (the $\mathrm{R}+$ $\underline{\mathrm{R}} \mathrm{Gp}$ condition), despite the fact that both conditions had identical second new-search displays.

Effects of foreknowledge when the target's color differed from that of homogeneous previews: $\mathbf{G}+$

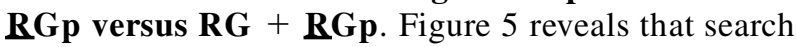
was most efficient in the preview $\mathrm{G}+\underline{\mathrm{R}} \mathrm{Gp}$ condition (known red target in an overall minority set). To verify this statistically, performance in this condition was compared with the next best condition: $R G+\underline{R G p}$. This comparison revealed an overall mean difference of $72 \mathrm{msec}$, leading to a significant main effect of condition $[F(1,16)=17.742, p<.01]$. The main effect of display size was also significant $[F(1,16)=46.132, p<.001]$, as was the condition $\times$ display size interaction $[F(1,16)=$ $5.118, p<.05]$. Search in the $\mathrm{G}+\underline{\mathrm{R}} \mathrm{Gp}$ condition was quicker and more efficient than that in the $R G+\underline{R} G p$ condition. Again, it should be noted that the second search displays were identical.

Effects of target color. To assess the effects of target color in the no-foreknowledge condition, the RG $+\mathrm{RG}$ and $\mathrm{R}+\mathrm{RG}$ conditions were compared, with target color as a factor. The main effect of condition was not significant $[F(1,16)=1.469, p=.243]$, but the main effects both of display size $[F(1,16)=59.728, p<.001]$ and of target color $[F(1,16)=14.219, p<.01]$ were significant. There were three interactions involving target color: con-

Table 3

The Experimental Conditions, Color Combinations, and Target Color for Experiment 3

\begin{tabular}{lcccl}
\hline Condition & Preview Display & Search Display & Foreknowledge & Target Color \\
\hline RG + G & RG & G & $\checkmark$ & green \\
G $+\underline{\text { RGp }}$ & G & RG & $\checkmark$ & red \\
RG + RG & RG & RG & $\times$ & either (50\%) \\
RG $+\underline{\text { RGp }}$ & RG & RG & $\checkmark$ & red or green \\
R + RG & R & RG & $\times$ & either (50\%) \\
R $+\underline{\text { R }}$ p & R & RG & $\checkmark$ & red \\
\hline
\end{tabular}

Note-The notation in the foreknowledge column refers to whether, in that individual condition, the observers were provided with foreknowledge (denoted by a $\checkmark$ ) or were not provided with foreknowledge (denoted by a $\times$ ). 


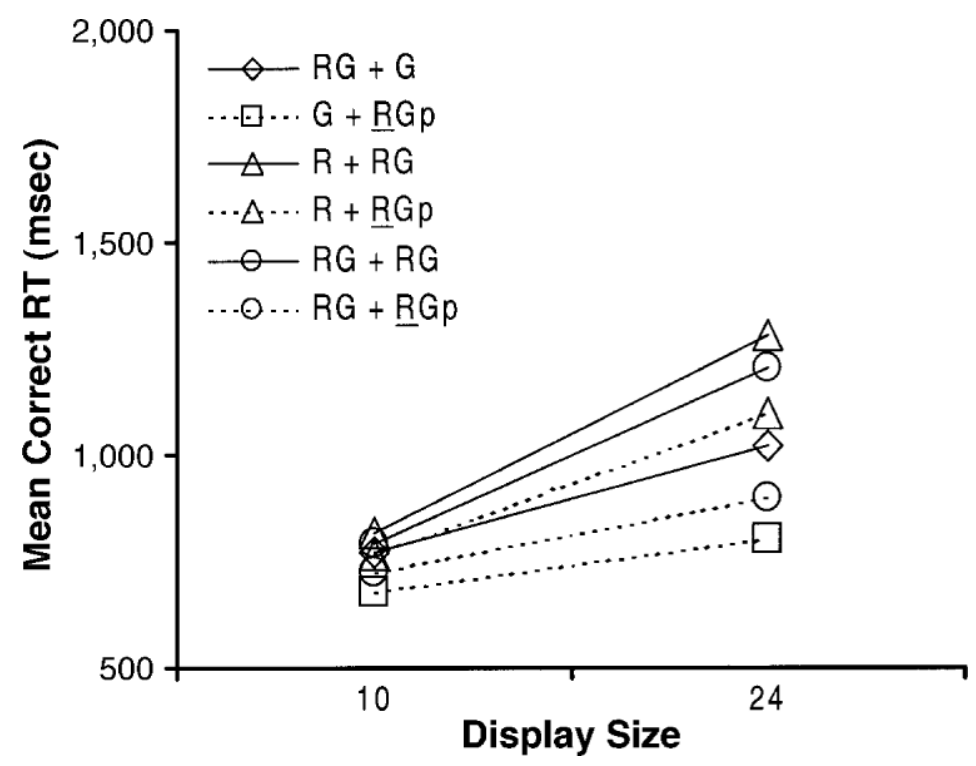

Figure 5. Mean correct reaction time (RT) for all conditions expressed across display size for Experiment 3 (see the text for further details).

dition $\times$ target color $[F(1,16)=12.003, p<.01]$, display size $\times$ target color $[F(1,16)=11.329, p<.01]$, and condition $\times$ display size $\times$ target color $[F(1,16)=11.307$, $p<.01]$. Search for the red targets in the $\mathrm{R}+\mathrm{RG}$ condition was greatly slowed, in comparison with green targets, and it was slowed relative to both red and green targets in the $\mathrm{RG}+\mathrm{RG}$ condition. The long RTs to red targets in the $\mathrm{R}+\mathrm{RG}$ condition is consistent with a negative effect of color carryover (see Experiment 2).

Effects of color foreknowledge with a minority color set. In the $G+\underline{R} G p$ condition, the participants searched for a target in a known color that was also part of a minority color set in the overall (final) search display (in this case, red). To test whether foreknowledge of the target color was effective over and above the effects of being in a minority set, performance was compared with that in the $\mathrm{R}+\mathrm{RG}$ preview baseline condition, when the target was in a minority color (green, in this case). The main effects of both condition and display size were significant $[F(1,16)=25.159, p<.001$, and $F(1,16)=51.232, p<.001$, respectively]. The condition $\times$ display size interaction was also significant $[F(1,16)=13.026, p<.01]$. There was an overall benefit of $183 \mathrm{msec}$ from color foreknowledge (in the $\mathrm{G}+$ $\underline{R} \mathrm{gp}$ condition vs. the $\mathrm{R}+\mathrm{RG}$ condition). This advantage increased with the display size.

Errors. The overall experimental error rate was low at $3.57 \%$ and followed the same pattern as RTs (see Figure 6).

\section{Discussion}

\section{New-Object Capture and Inhibitory Carryover}

There are several results of interest. The general pattern of the data from Experiment 3 replicated those from both Experiments 1 and 2. Here, prior knowledge of the target's color in the $\mathrm{RG}+\underline{\mathrm{R}} \mathrm{Gp}$ condition, in relation to the $R G+R G$ condition, produced an overall significant RT improvement of $187 \mathrm{msec}$ and improved search efficiency (e.g., there was a reduced effect of display size). There was also a reliable improvement in search efficiency from foreknowledge of the target's color in the $\mathrm{R}+\mathrm{RG}$ condition (116 msec), although this improvement was less than that in the RG $+\mathrm{RG}$ condition. Indeed, even when foreknowledge of the target's color was specified, search in the $\mathrm{R}+\underline{\mathrm{R} G p}$ condition was significantly slower (and less efficient) than that in the RG + $\underline{R} G p$ condition, despite the fact that both conditions had identical second-set search displays. This result contradicts accounts based on prioritized new-object capture by the second display (e.g., Donk \& Theeuwes, 2001).

Instead, the data suggest that there is a negative carryover effect when the target's properties match a property subject to inhibition in Display 1. When Display 1 contains items in a single color, participants may attempt to optimize selection of the new stimuli by inhibiting the old items on the basis of their shared property-color. This reduces the full benefit gained by having foreknowledge of the target's color, found in the $\mathrm{RG}+\underline{\mathrm{R} G p}$ condition. Indeed, as in Experiment 2, performance in the $\mathrm{R}+\underline{\mathrm{R}} \mathrm{gp}$ condition was no more efficient than that in the $R G+G$ preview treatment. In the $R G+G$ preview condition, there were more new items in the target's color than there were in the $\mathrm{R}+\underline{\mathrm{R}} \mathrm{Gp}$ condition, so selective search of the new items in the target's color should have generated more efficient search in the $\mathrm{R}+$ $\underline{R} G p$ condition. If anything, the data went in the opposite direction [although the condition $\times$ display size interaction just failed to reach significance; $F(1,16)=2.58$, $p=.07]$. The relatively poor performance in the $\mathrm{RG}+$ $\underline{R} G$ p condition is consistent with a form of inhibitory 


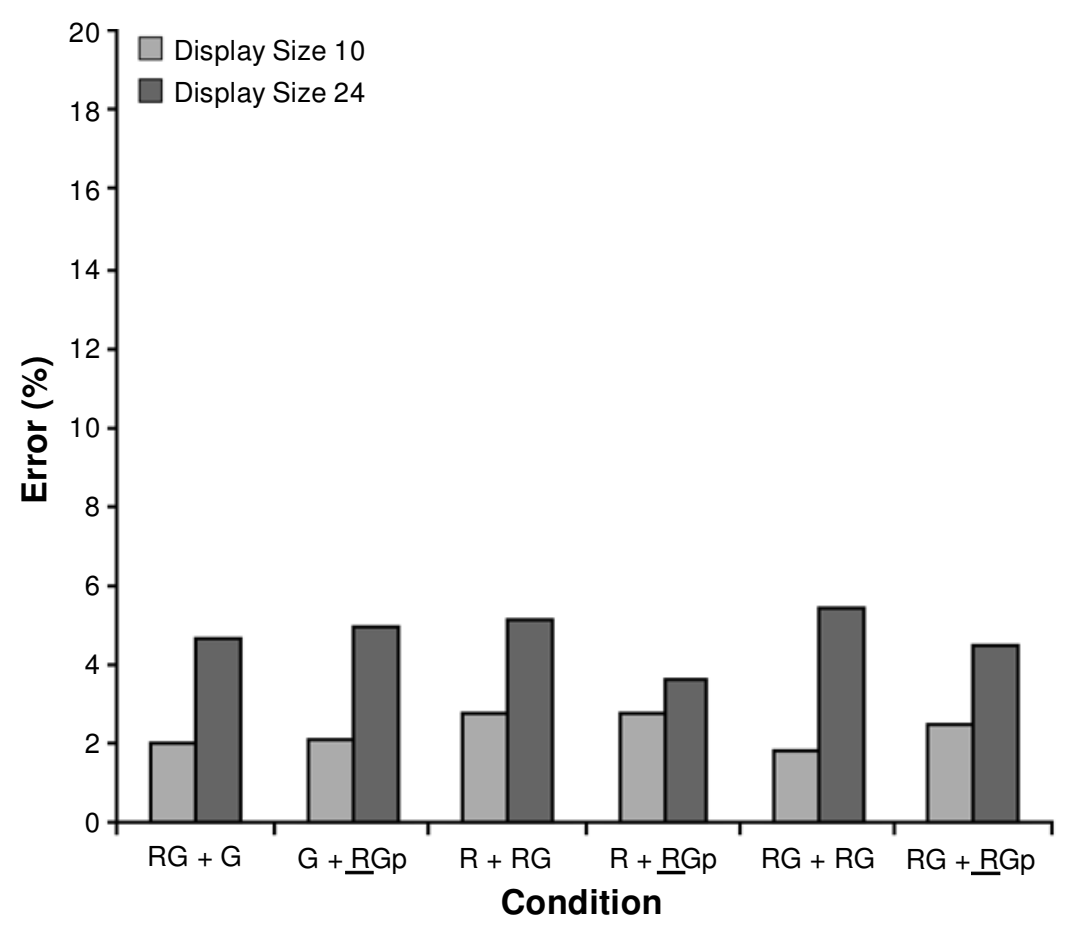

Figure 6. Errors (expressed as percentages) for each condition and display size in Experiment 3.

carryover, based on the color shared by the preview and the target.

\section{Effects of Target Color Probability}

Although our data fit with an account in terms of color-based grouping and inhibition, it remains possible that other mechanisms could be responsible. For instance, there may have been effects that were due to variations in the probability of the target's being a particular color. In the $\mathrm{R}+\mathrm{RG}$ condition, the overall probability (based on the number of items of each group in the display) that the target was in the green group was higher than the overall probability that it was in the red group (it was approximately triple). Could this have generated a strategy in which the participants deliberately prioritized search for the minority color green?

There are several reasons that suggest that probability alone was not crucial. First, in other experiments (Braithwaite et al., 2002), we used full-set baselines in which the color item probabilities matched those in the overall display in the $\mathrm{R}+\mathrm{RG}$ condition, yet we failed to find differences in the discrimination of targets in the majority (red) and minority (green) colors. Second, the data from the $\mathrm{G}+\underline{\mathrm{R}} \mathrm{Gp}$ condition (in Experiment 3 ) contradict the overall item probability proposal. In this condition, the target was in the minority color (red), but it was also known. Performance was substantially better than that to minority color targets in the $\mathrm{R}+\mathrm{RG}$ condition, whose color was not predictable. However, if the participants were predicting the target color on the basis of variations in probability in the $\mathrm{R}+\mathrm{RG}$ condition, performance should be as efficient as that in the $G+\underline{R} G p$ condition. Therefore, if the new minority group was being optimized, it is difficult to see why such large search advantages occurred when the observers were asked to prioritize the minority group (which was presumably already being prioritized if a strategy based on overall item probability was in place). Clearly, the results from Experiment 3 show that this was not the case.

Despite these reservations, we sought to test the probability account directly in Experiment 4 . We compared the $\mathrm{R}+\mathrm{RG}$ preview condition from Experiments 2 and 3 (with overall unequal target color probabilities) with a variant of the same condition in which (overall) the target was equally often red or green. To do this, we made the target more often red than green in the second search displays. If the overall item probability was crucial to the effects reported here, search performance for red and green targets in the equal probability $\mathrm{R}+\mathrm{RG}$ condition should have been equal. The detection of red targets should also have been benefitted relative to the standard $\mathrm{R}+\mathrm{RG}$ condition, since they are now no longer low-probability events.

\section{EXPERIMENT 4 Varying Target Color Probability}

\section{Method}

\section{Participants}

Thirteen participants from the University of Birmingham ( 5 female; age range, 21-35 years; mean age, 25 years; all were right- 
handed) took part for a small payment. All reported that they had normal or corrected-to-normal vision.

\section{Stimuli and Apparatus}

All the stimuli and the apparatus were similar to the arrays used in the previous experiments. The only difference here was the manipulation of target color group probability across both the conditions.

\section{Design and Procedure}

A $2 \times 2$ (condition $\times$ display size) within-subjects design was used. Each condition consisted of an $\mathrm{R}+\mathrm{RG}$ preview display. However, the conditions differed in terms of the likelihood that the target would be a new green or a new red item. In the first condition, we maintained the probability from the previous experiments; overall, the target was more likely to be green than red. To maintain consistency of labeling, we refer to this as $\mathrm{R}+\mathrm{RG}$. Coupled to this was the similar preview condition with an equal probability of the target's being red or green ( $\mathrm{R}+\mathrm{RGeq})$.

The numbers of trials on which the target was red or green across the conditions were as follows. There was 40 trials per display size ( 80 overall). For the standard condition $(\mathrm{R}+\mathrm{RG})$, there were 20 red targets and 20 green (for each display size). For the $\mathrm{R}+\mathrm{RGeq}$ condition, there were 30 red targets and 10 green targets (per display size). Conditions were blocked, and block order was randomized across participants. The participants were told that there were differences between the conditions, and they were simply instructed to remain fixated until the search display was presented. They were instructed that the target would always be a new item in the second display and that it could be red or green. In other respects, the procedure followed that of the previously reported experiments.

\section{Results}

Overall mean correct RTs for both conditions are plotted as a function of display size in Figure 7. These RTs were entered into an overall $2 \times 2$ within-subjects ANOVA. This revealed only a significant main effect of display size $[F(1,12)=24.509, p<.001]$. Both the main effect of condition $[F(1,12)=0.580, p=.461]$ and the condition $\times$ display size interaction $[F(1,12)=0.580$, $p=.461]$ failed to approach significance.

RTs were then broken down further as a function of target color and were entered into a $2 \times 2 \times 2$ (condition $\times$ display size $\times$ target color) ANOVA. The main effect of condition was not significant $[F(1,12)=2.556, p=$ .136]. Main effects of both display size $[F(1,12)=$ $30.561, p<.001]$ and target color $[F(1,12)=12.200$, $p<.01]$ were significant. Only the display size $\times$ target color interaction was significant $[F(1,12)=21.866, p<$ .01 ; all other interactions, $\left.F_{\mathrm{S}}<4.5\right]$. There was no significant three-way interaction $(F<1)$. Figure 8 shows the RTs for both red and green targets from both preview conditions as a function of the display size. Targets that carried the color of the preview were more difficult to discriminate than targets that were in a different color. This occurred both when the target was equally likely to be either color in the search display $(\mathrm{R}+\mathrm{RG})$ and when it was equally likely in the overall display ( $\mathrm{R}+\mathrm{RGeq})$.

\section{Errors}

The overall error rate was low at $4.14 \%$. There were no interactions for the error data involving target color, so errors were analyzed as a function of condition and display size in an overall $2 \times 2$ ANOVA. This revealed only a significant main effect of display size $[F(1,12)=$ $5.235, p<.05]$. Both the main effect of condition and the condition $\times$ display size interaction were not significant $[F(1,12)=0.658, p=.435$, and $F(1,12)=2.556$, $p=.136$, respectively; see Figure 9].

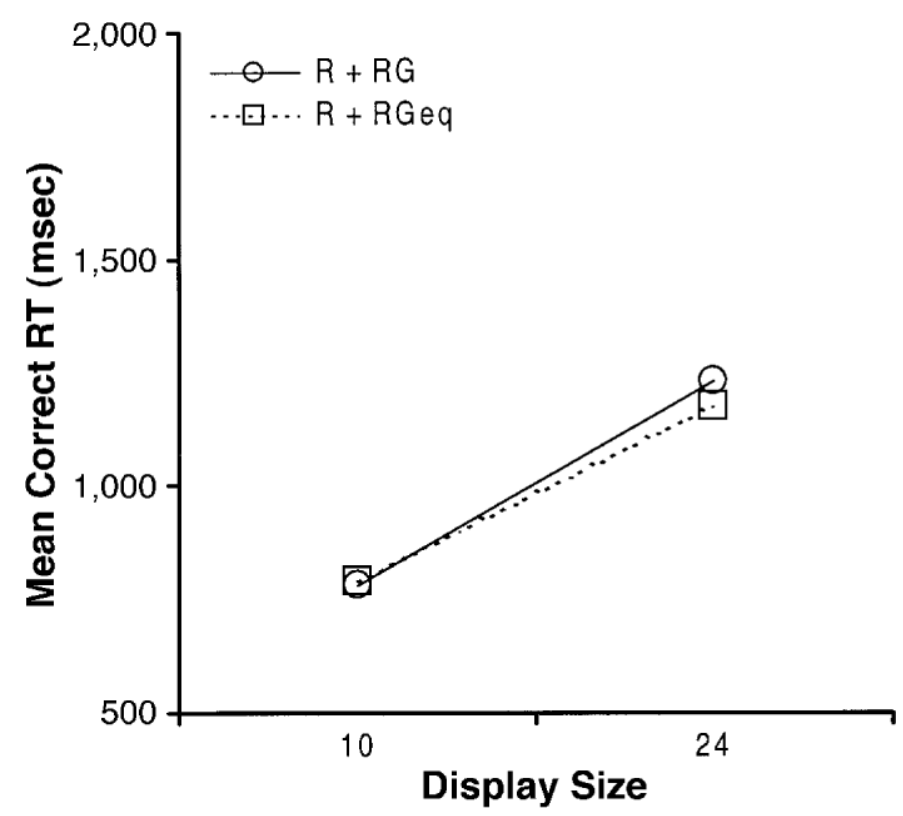

Figure 7. Overall reaction times (RTs) for both the $R+R G$ and the R + RGeq preview conditions in Experiment 4. 


\section{Discussion}

The results from Experiment 4 are clear. Manipulating the probability that the target was in a particular color did not significantly influence search overall. Even more interestingly, targets that matched the color of the preview were difficult to discriminate, and this held across both the R + RG and R + RGeq conditions. Making the target equally likely to be either color, overall, had no impact on performance. Along with our other data, where we matched probabilities in the full-set baseline condition to those in the $\mathrm{R}+\mathrm{RG}$ condition, these results suggest that the effects were not due to biases induced by variations in the target's being a particular color. However, the results are consistent with the idea of a negative color carryover effect from previews. This carryover makes it difficult to discriminate targets having the color of the preview, even if the probability that the target is that color is matched overall to its being the new color (and even when, in the search display, the target is much more likely to be the color of the preview, relative to the new color presented).

\section{GENERAL DISCUSSION}

We have found substantial preview benefits, in a serial search task, when half the distractors in a search set preceded a second display of distractors plus the target. This matches the results of prior studies that used mixedletter displays when search was difficult and likely included serial components (Olivers et al., 1999; Theeuwes et al., 1998). We have also shown that this preview ben- efit is modulated by the colors of the letters and by foreknowledge of the target color. Collectively, our evidence and conclusions can be summarized as follows.

1. Color in preview search is important. The inhibitory template is not feature blind.

2 . The results cannot be explained simply in terms of onset capture (e.g., Donk \& Theeuwes, 2001).

3. Color similarity within Display 1 and between Displays 1 and 2 is important when an anticipatory set is used (Experiments 2 and 3). This provides evidence for an anticipatory set to the target, in addition to any negative set against distractors in preview search.

4. The impact of the target carrying the color of the preview can be reduced when an anticipatory set is used (Experiments 2 and 3). This also provides evidence for an anticipatory set to the target, in addition to any negative set against distractors in preview search.

5. The beneficial effect of giving foreknowledge of the target's color is reduced if the target carries the color of the preview (Experiments 2 and 3). There is some impact of a negative carryover of the preview's color, which occurs in parallel with participants' adopting an anticipatory set to the target color.

6 . These results cannot be explained in terms of distractor ratio or search guided by the overall probability that the target will be in a particular color (Experiment 4).

\section{Evidence for a Positive Anticipatory Set}

In a full-set baseline condition, foreknowledge of the target color improved performance, bringing it down to

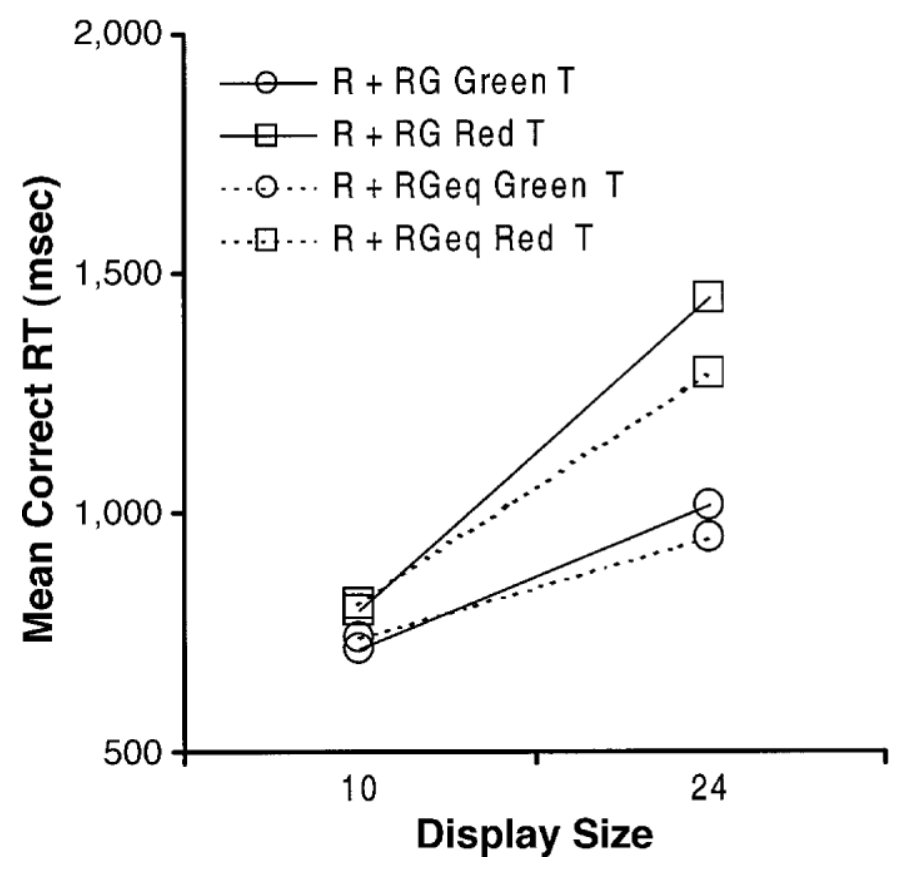

Figure 8. Reaction time (RTs) broken down as a function of target color (red or green targets) for both the $R+R G$ and the $R+R G e q$ preview conditions in Experiment 4. 


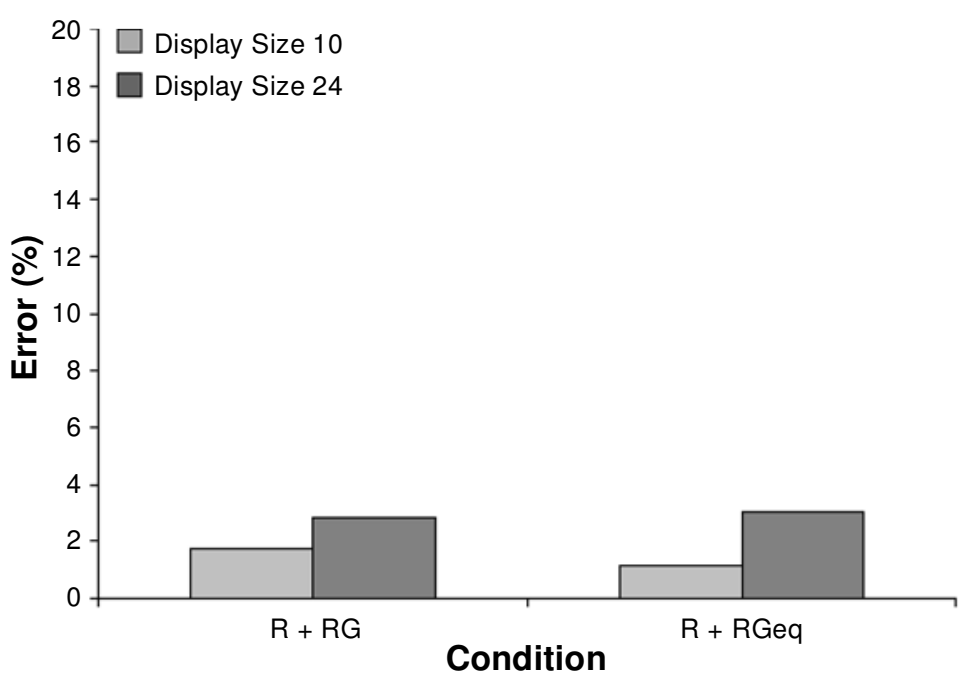

Figure 9. Error percentages for both conditions in Experiment 4.

the level found when only half the distractors, in one color, were present (Experiment 1). This demonstrates that the participants were able to use foreknowledge of the target color to guide search through the present displays (cf. Bacon \& Egeth, 1997; Egeth et al., 1984; Kaptein et al., 1995; Moore \& Egeth, 1998). We also demonstrated that the participants could use foreknowledge of the target's color to guide search in preview displays. In all cases, the magnitude of the preview benefit increased when the target color was known, as compared with when it was unknown. This is consistent with participants' being able to adopt a positive anticipatory set, to help them prioritize the selection of new items having the same color as the target.

\section{Evidence Against Prioritized New-Object Capture (Alone)}

As we noted in the introduction, one account of the preview benefit in search is that it is due to attentional capture by the new search display (Donk \& Theeuwes, 2001). Our evidence for effects of target color foreknowledge suggests that attentional capture alone does not provide a sufficient account of the data. Nevertheless, the preview benefit could be the result of prioritized attentional capture, based on an anticipatory set for the new search displays.

In our view, the most important aspect of the present results is our demonstration that even a prioritized attentional capture is not sufficient. We compared preview conditions in a set in which the second displays were identical and the target color was always known. Prioritized attentional capture by the new items should lead to equivalent performance in these conditions. The data clearly refute this. In particular, performance differed according to whether the old items in preview search had single or mixed colors and according to whether the tar- get carried the color of the preview. When the previews had a single color, it was difficult to detect a target that had the same color as the old items, even when the target's color was prespecified. Search was also then no more efficient than that in a full-set baseline condition (with the target color known [fullp]) and than that in a preview condition in which the items in the second set all had the same color $(R G+G)$. In the last conditions, there were more new items sharing the target's color than in the preview with a homogeneous first set $(R+\underline{R} G p)$. This indicates that the participants failed to select just the new items in the target's color (Experiments 2 and 3 ). The old items had an impact on search when they shared a feature value with the new stimuli.

\section{Inhibitory Color Carryover or Grouping Alone?}

We have suggested that the difficulty in discriminating a target that was the same color as the preview was due to a carryover of inhibition from the preview to the search display. The effect was also influenced by grouping between the items in the preview display. For example, search for a red target was worse in the R + RG condition than in the RG + RG condition (Experiment 3 ), even though the search display was the same in both instances. We suggest that this occurred because, when items in the preview had the same color, they could be grouped and inhibited using that common feature. This would then have a negative impact on search for a target carrying the inhibited color.

However, we need also to ask whether it is necessary to propose an inhibitory mechanism to explain these data, over and above any effects owing to grouping per se. For example, it may be that there is some tendency to group old and new stimuli on the basis of their having a common color. This tendency may be increased when the old items are homogeneous and are already grouped on that di- 
mension (in the $R+R G$ condition relative to $R G+R G$ ). Grouping a new target with the old stimuli would impair performance, if it then made it part of a low-priority set for search. We suggest that a simple grouping account alone is not sufficient to account for all the results presented here and elsewhere.

For instance, Experiment 3 provides evidence for an inhibitory component to grouping and selection over time. In this experiment, we found that color homogeneity in the old set facilitated search when the target's color was known and different from that of the old distractors (the $\mathrm{G}+\underline{\mathrm{R}} \mathrm{Gp}$ condition relative to the $\mathrm{RG}+\underline{\mathrm{R}} \mathrm{Gp}$ condition). In this case, any carryover of inhibition would aid the segmentation of items in the target's color from distractors (by helping the suppression of the distractors). These results, then, suggest that, although an anticipatory set for targets can contribute to the preview benefit, it is not sufficient. In particular, in addition to any anticipatory set, search may be made efficient by the inhibition of distractors. This is in accord with inhibitory accounts of the preview benefit, such as the visual marking theory of Watson and Humphreys (1997). Along with other recent data, our findings extend the original marking accounts by indicating that marking is not simply location based but can also be applied to the features of old stimuli (Braithwaite et al., 2002, in press; Gibson \& Jiang, 2001; Olivers \& Humphreys, 2002).

Furthermore, as we have noted, we have run other studies in which we used a full-set baseline matched to the preview condition R + RG (Braithwaite et al., 2002). This baseline should at least match the strength of color grouping to that in the preview condition (if anything, color grouping should be stronger in the baseline, because all the items then appear simultaneously). Despite this, detection of a red target in the preview condition was worse than that in the full-set baseline condition (indeed, detection in the preview was worse than that in a full-set baseline that employed even more extreme distractor ratios than those present in the R $+\mathrm{RG}$ condition; see Braithwaite et al., 2002). This is difficult to understand in terms of grouping processes alone. Instead, it indicates that, in addition to effects of color similarity, there is an impact of the target's carrying the color specifically of the old items, which (we suggest) are deprioritized for search. We propose that old items are deprioritized by being inhibited.

As we pointed out in the introduction, an inhibitory account also fits with other data on poor detection of probes at locations of old stimuli (Olivers \& Humphreys, 2002; Watson \& Humphreys, 2000) and on color carryover effects. The color carryover effects in Olivers and Humphreys occurred across trials (when the search display on trial $n+1$ had the color of the preview on trial $n)$. It is difficult to attribute such effects to grouping (preview and search displays were separated by an intertrial interval in Olivers \& Humphreys, 2002), but they are consistent with negative carryover based on an inhibited, shared feature.

\section{Effects of Target-Distractor Color Ratio}

Another alternative interpretation of the results is that they reflect the target-distractor color ratio, and not inhibitory processes in preview search. For example, red targets may not be advantaged as much in the $\mathrm{R}+\underline{\mathrm{R} G p}$

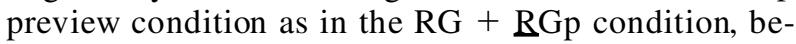
cause they are part of a larger group of items in the display overall, once the second search display has been presented. However, although effects of distractor ratio may be present, there are a number of compelling reasons for doubting that this suggestion is crucially responsible for the effects observed here. There is direct evidence from the present experiments that the target-distractor color ratio is not critical. Consider the results from Experiment 2 for the $\mathrm{R}+\mathrm{G}$ and $\mathrm{R}+\mathrm{RG}$ preview conditions. Here, we compared performance for new green targets in the $\mathrm{R}+\mathrm{G}$ condition with performance for green targets in the $\mathrm{R}+\mathrm{RG}$ condition. In the latter case, the green targets were also the minority color group in the final overall display. If the ratio of the uneven color groups was important, we would expect RTs to be quicker in the $\mathrm{R}+$ $\mathrm{RG}$ condition than in the $\mathrm{R}+\mathrm{G}$ condition (since search is based on fewer items; Bacon \& Egeth, 1997; Egeth et al., 1984; Kaptein et al., 1995; Moore \& Egeth, 1998). This did not happen. Performance was no more efficient for minority targets in the $\mathrm{R}+\mathrm{RG}$ condition than for targets in the $\mathrm{R}+\mathrm{G}$ condition. ${ }^{4,5}$

Second, Braithwaite et al. (2002) failed to find a distractor ratio effect in a baseline experiment with the same stimuli as those used here, even when a more extreme bias was employed in the displays. One might expect, from either a bottom-up (Cave \& Wolfe, 1990) or a top-down (Bacon \& Egeth, 1997; Egeth et al., 1984; Kaptein et al., 1995; Moore \& Egeth, 1998) perspective that an increased bias may facilitate the role of smallgroup priority in search. This did not happen; RTs for targets in the small minority group were no more efficient that those for targets in the larger majority group. One reason for this may be the relatively small display sizes used here. More dense arrays may raise the saliency of the minority color group (e.g., Bravo \& Nakayama, 1992; Cave, 1999; Cave \& Wolfe, 1990), encouraging top-down prioritization based on color. Indeed, it is more common for distractor ratio experiments to use much larger display sizes than those used here (e.g., up to 64 items; Bacon \& Egeth, 1997; Poisson \& Wilkinson, 1992; Zohary \& Hochstein, 1989). Nevertheless, the fact that we found only a small presence of distractor ratio in a baseline condition emphasizes that the present effects are due more to the preview condition than to the targetdistractor color ratio alone. ${ }^{6}$

In support of these suggestions, Sobel and Cave (in press) provided similar evidence that smaller groups are less salient with smaller display sizes, relative to larger, more dense displays. However, these researchers also demonstrated that in some circumstances (e.g., conjunction search), robust effects of uneven ratio can emerge for display sizes not too dissimilar from those used here. 
One reason for this discrepancy may well be the task differences between their study and the present one (e.g., that color is not a defining attribute of the target and cannot enter a target set in the $\mathrm{R}+\mathrm{RG}$ case). ${ }^{7}$

We also presented new data here against an account of search based on the overall item probability that the target was in a particular color in the final display. Search could be slowed for red targets in the $R+R G$ preview condition because targets were unlikely to be red, when all the items in the final display are taken into account. In Experiment 4, we matched the probability that the target was red and green in this preview condition, yet we still found that red targets (e.g., targets carrying the color of the preview) were more difficult to discriminate. Probability effects cannot explain the data. The results from Experiment 4 also serve to emphasize the argument against a new-object capture account. When we matched the probability of the target's being in either color overall, we made red targets much more likely than green targets in the new search display. Yet, even with this probability bias in the new display, red targets were still relatively difficult to identify. A new object capture account makes exactly the opposite prediction. To summarize, although the displays used for some of the conditions reported here produce an effect of overall ratio (in the baseline conditions consisting of a similar bias), this effect is small and has often failed to reach significance (see Braithwaite et al., 2002). Therefore, it appears that the effect of uneven grouping in the displays, although present, is not crucial to the color-based effects reported here.

\section{On the Relations Between Excitatory and Inhibitory Sets in Search}

Before expanding the idea of dual attentional sets, perhaps it is worth considering whether a single (inhibitory/ excitatory) mechanism could account for the results presented across the experiments here. In the color foreknowledge condition of the present study, the target was always a known color. Our results indicate that for baseline and preview conditions, participants could use this advanced information to facilitate search, consistent with their adopting an anticipatory set that restricts search to items in the expected color (e.g., Bacon \& Egeth, 1994, 1997; Egeth et al., 1984; Kaptein et al., 1995; Moore \& Egeth, 1998). However, the failure to confine search to new items in the target's color, when the old items had a single color, suggests that there was also color-based inhibition of old items. This occurred even when the old items were the same color as the anticipated target color. Apparently, then, there was joint adoption of an anticipatory color set (for new items) and an inhibitory color set (for old items). These forms of set may be adopted in parallel, even though they may operate in opposite ways on search. If a simple unitary mechanism (e.g., facilitatory) process had been operating, then we might have expected the advantage from color foreknowledge in the $\mathrm{R}+\underline{\mathrm{R}} \mathrm{Gp}$ condition to be optimal; clearly, it was not. It would seem that although an antici- patory set for targets can indeed contribute to the preview benefit, it is, on its own, not sufficient to explain all of the effects reported here. Furthermore, it is unclear how a unitary (inhibitory) process could account for the different patterns of performance between simultaneous baseline and preview conditions that consist of the same displays overall (once both presentations are considered for the previews). Instead, to account for the results presented here, we propose that there are dual attentional sets-one inhibitory and directed toward old information and one facilitatory and directed toward new information.

In addition to the above points, it is also unlikely that in the $\mathrm{R}+\mathrm{RG}$ condition, the participants were simply setting themselves to prioritize new green items. First, there would be little reason to do so, since the target was equally often a new red item. Second, the large improvements from target color foreknowledge for new green (e.g., new minority) targets would not be expected if that group was already being optimized (see the above sections on color grouping for a fuller discussion of this). Again, we propose that the results presented here support the existence of dual attentional sets' mediating the preview benefit.

How do our suggestions of multiple attentional sets relate to other proposed anticipatory mechanisms? $\mathrm{Nu}$ merous studies have shown that prioritization in search can be influenced by a top-down attentional set adopted by the observer (Bacon \& Egeth, 1994; Folk \& Remington, 1996; Folk et al., 1992, 1993; Folk et al., 1994; Gibson \& Kelsey, 1998; Yantis \& Egeth, 1999), where different features may be assigned contrasting attentional weights (e.g., for onsets vs. color). A top-down attentional set may also be involved in guiding search within a display to items of a specified color (Bacon \& Egeth, 1997; Egeth et al., 1984; Kaptein et al., 1995; Moore \& Egeth, 1998). All of these accounts have typically proposed that prioritization involves the anticipatory activation of relevant stimulus dimensions (Bacon \& Egeth, 1997; Folk et al., 1992, 1993; Folk et al., 1994; Kaptein et al., 1995; Moore \& Egeth, 1998). Indeed, as far as prioritizing search to new stimuli is concerned, Folk and Remington (1996) have argued that there is little evidence to consider an inhibitory component (see Moore \& Egeth, 1998, for similar conclusions in relation to facilitation of relevant color feature search).

In contrast to this, we propose a role for two complementary attentional sets - one negative (inhibitory) and directed toward old, irrelevant information and one positive (facilitatory) and directed toward new, relevant stimuli. In particular, it is difficult for an anticipatory account to explain the slow search when the old items had a homogeneous color-a result consistent with negative color carryover of inhibition applied to the color of the preview. In the present study, the color carryover was clearest when the preview had a homogeneous color. This, in turn, suggests that color grouping influences distractor rejection (cf. Duncan \& Humphreys, 1989). We propose further that preview search is sensitive to group- 
ing between the old items and that it is not purely location based (contrary to Watson \& Humphreys, 1997, 2002).

The point above is not a trivial one in relation to our suggestions here. We are outlining a strong role for color grouping in preview search, a process that may well itself involve suppressive components (Duncan \& Humphreys, 1989). Coupled to this, we are further advocating that selection over time brings further inhibitory processes to bear, perhaps on grouped representations, perhaps in the form of direct feature map inhibition (see below) ${ }^{8}$ The negative impact of these processes can be overcome to some degree if an anticipatory set can be initiated.

\section{On the Functional Role of Color Grouping in Preview Search}

Although we have provided positive evidence for color effects in preview search, other recent results fail to fit this idea. For example, Watson and Humphreys (2002) investigated the effects of different types of change applied to old items when new items appear in preview search (see also Watson \& Humphreys, 1997). When old distractors changed their color, search was unaffected. In contrast, search was disrupted when the old items changed shape. Watson and Humphreys's (2002) findings are consistent with preview search's being based on inhibition of a dynamic detection system, sensitive to shape but not to color change. Inhibition of activation in this system created by old items would increase the signal-to-noise ratio when new stimuli appear. This fits with the findings of Donk and Theeuwes (2001), who failed to observe a preview benefit when the new items were isoluminant with the background. Isoluminant targets would not activate a detection system sensitive to dynamic luminance change.

How can we reconcile these different results? One possibility is that old distractors are rejected from search, using any common property that distinguishes them from new items. This could include inhibition of a color map, when the old items group by color (Treisman, 1993; Treisman \& Sato, 1990), or inhibition of a group formed by common color (Duncan \& Humphreys, 1989). It will also include inhibition of the locations of the old items within a dynamic detection system. The color- and location-based inhibition may be applied through independent templates, as is indicated in Figure 10 (see also Watson \& Humphreys, 1998). In each case, inhibition operates in parallel across the occupied locations. Whether or not the new items are prioritized in search is dependent on their levels of activation in the dynamic detection system, relative to those of old items. To explain the results, we suggest that locations of items within their color map are linked to locations in the dynamic detection system. If a color map (or alternatively, a color group) is inhibited, new items in that color may be relatively difficult to detect, owing to spreading suppression from the inhibited color map to locations in the dynamic detection system (cf. Duncan \& Humphreys, 1989). This is consistent with the data reported here.

When the color of the old items changes, activation in the color maps may be reset, but inhibition from the location template may be retained within the dynamic detection system. In these circumstances, the preview effect should remain relatively intact. In contrast, changes within the dynamic system itself (owing to altering the shapes of the old items) will disrupt search. This is consistent with the results on the effects of color and dynamic shape change reported by Watson and Humphreys (2002). Furthermore, the effects of target color foreknowledge may be modulated through a separate anticipatory template (see Figure 10). This can modulate activation in the color map, speeding search to new targets.

\section{Comparisons With Other Proposed Inhibitory Mechanisms in Selection}

The proposed properties of visual marking seem to distinguish this mechanism of selection from other, alternative mechanisms posited in the literature (see Olivers et al., 1999, and Watson \& Humphreys, 1997, for discussions on this topic). For instance, it is unlikely that the present results are due to inhibition of return (IOR) applied serially to the locations of the old stimuli. Olivers, Humphreys, Heinke, and Cooper (2002) directly compared a serial IOR account with that of visual marking, applied in parallel across the old items. The task was to find a target letter among other, randomly presented letters (as here). In the IOR condition, the target could appear in the preview or in the second display on a trial. Hence, the participants searched the first set of items for the target. If it was not present, the participants pressed a key, when ready, to expose the second display. In this condition, IOR should be applied to each old location, to enable serial search to operate (cf. Klein, 2000). Despite this, Olivers et al. (2002) found only a small benefit for this condition, relative to a full-set baseline condition. Performance was much better than this when the participants knew that the target would be in the second display, when they could set themselves to ignore the old items. There was a strong preview benefit when a marking process was encouraged (a set to prioritize the new and to ignore the preview display), and not when serial IOR should have occurred.

There are further reasons for doubting an IOR explanation of the present results. For instance, feature-based (color) effects in IOR are at best moderate, with several investigators failing to find effects in an IOR paradigm (e.g., Kwak \& Egeth, 1992). Also, recent studies have suggested that only around five locations can be subject to IOR in a sequential visual search task at any one time (and even this decreases rapidly over time; Snyder \& Kingstone, 2000). Against this, the present results indicated that up to 12 old items could be ignored in preview search, and other investigators have found benefits with up to 15 old items (Theeuwes et al., 1998). The capacity limits for marking and serial IOR seem very different. 


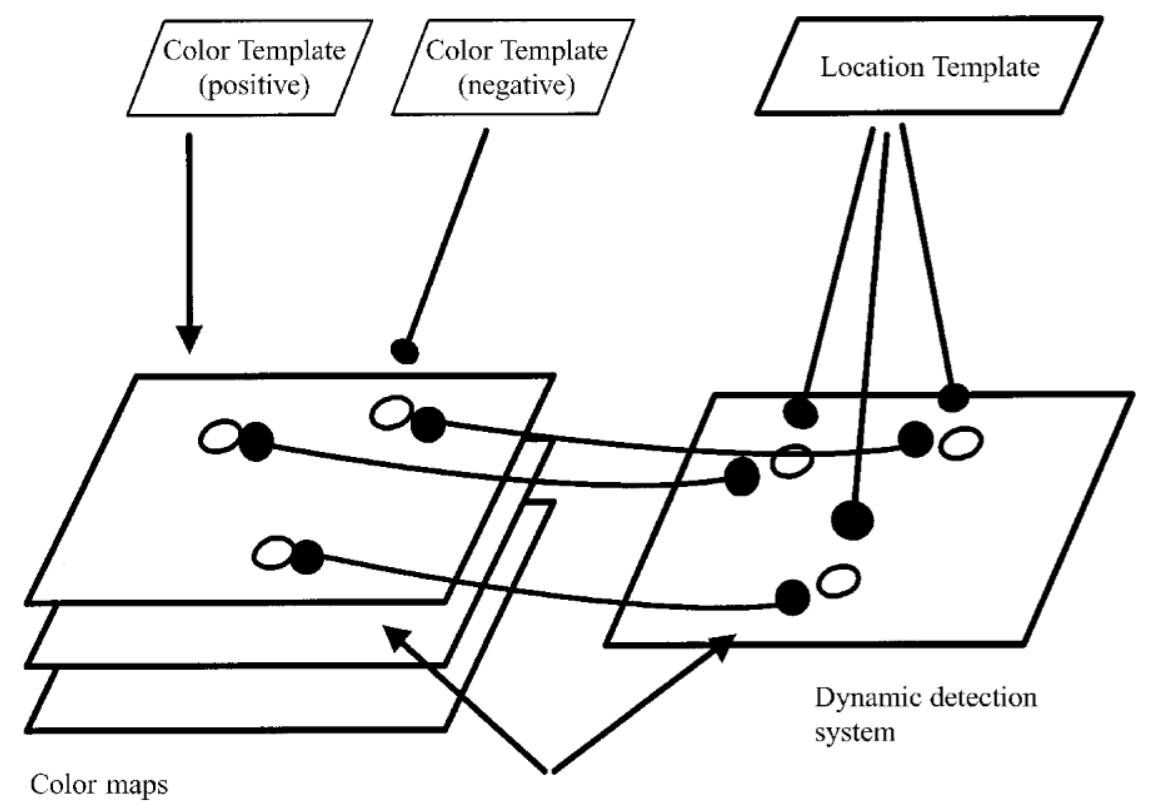

Inhibitory connections

Figure 10. A schematic illustration outlining how a negative color-based carryover effect might take place within the framework outlined in the text. Activations associated with items are represented in the dynamic detection system and, from there, receive both location-based and feature-based coding. Thus, it is the locations and features in the dynamic detection system that receive attentional modulation. If a negative color set is being maintained by the observer, new items consisting of this feature will receive an inhibitory carryover from color maps. If participants have knowledge of the target's critical feature (e.g., color) and this is the same as that being inhibited by the negative color template, the facilitatory advantage of the positive template is reduced. Note that, in the example given, color maps are directly inhibited via the negative color set. Such a negative carryover could also occur in a more feature-guided (grouping) way (see the text). The findings do not differentiate between these architectural possibilities; the figure simply shows how a negative carryover might occur.

Interestingly, recent evidence indicates that IOR itself is not a simple process and that distinct location- and objectbased components may be dissociated (e.g., Tipper, Driver, \& Weaver, 1991). It is currently a matter of debate as to whether the location- and the object-based components of IOR are functionally the same. The evidence on visual marking to date suggests that it is not the same as serially applied, location-based IOR. It remains an open question, though, as to whether, at some level, marking uses the same mechanism as object-based IOR.

A further example of inhibitory processes in selection is that of negative priming. Numerous studies have argued that negative priming is the result of the active inhibition being applied to representations of distractors that compete for selection with the target (e.g., Neumann \& DeSchepper, 1991; Tipper, 1985). Interestingly, negative priming has been shown for both location (Tipper, Brehaut, \& Driver, 1990) and color (Tipper, Weaver, \& Houghton, 1994), so it is tempting to ask whether evidence from Watson and Humphreys $(1997,2002)$ suggests that evidence from negative priming is not critical. Watson and Humphreys (1997, 2002) had dynamical changes taking place either at the locations or in the properties of the old items. Such changes abolished marking completely when the old items changed at the time the new stimuli appeared. As has been pointed out by Olivers et al. (1999), in typical negative priming experiments, changes in old distractors are inherent in the paradigm, yet the negative priming effect seems unaffected. Furthermore, unlike the data presented here, negative priming studies have tended to show decreased inhibitory effects at increasing display sizes (Neumann \& DeSchepper, 1991), and these have never been shown for displays as large as those reported here. These seem to be important differences between the effects.

In addition, negative priming procedures typically measure responses to a previously rejected distractor when it subsequently becomes a target. In contrast, in preview search, used to study visual marking, responses are measured to new stimuli that have not previously been rejected as distractors. Performance on the new items is then measured in terms of whether the old items can be actively ignored. Nevertheless, the consequence of any suppression of distractors may lead to negative priming if stimuli sharing the suppressed property are subsequently presented as targets (see Olivers \& Humphreys, 2002, for evidence). Thus, the inhibitory mechanism might be shared across the procedures but 
measured in different ways. Indeed, the robustness of marking across varying display sizes might come about because, in preview search, old items may be treated (and inhibited) as a single group. Similarly, the detrimental effects of dynamic change may reflect temporal grouping when there is coincident change at new locations (Watson \& Humphreys, 2002). Hence, the contrasting effects of dynamic change and display size on marking and negative priming could still be consistent with involvement of the same inhibitory mechanism.

A recent study by Koshino (2001) is also relevant here. Using conjunctively defined stimuli, Koshino devised a prime-probe visual search paradigm. Here, stimulus facilitation or inhibition in prime displays was measured as a function of a carryover effect onto the probe display. Featural relationships between prime and probe displays were manipulated. Koshino reasoned that, if an excitatory mechanism was involved in search, it should be revealed as facilitation when the target and the distractors are repeated in the two successive displays. On the other hand, if an inhibitory mechanism was involved, suppression should occur when distractor features from the prime display determine the target in the following probe display. Koshino found evidence of both excitatory and inhibitory effects based on the features shared across prime and probe displays. Interestingly, the inhibitory effects were clearer at larger display sizes. This pattern of results matches those found here.

\section{Intentional Control and Location-Based Marking}

One perhaps more puzzling aspect of the present data is as follows. Targets here could have a known color. Given this, there would appear to have been little incentive to inhibit distractors that shared the target's color. That inhibition still occurred, then, seems to contradict the notion that marking is an intentional process. However, inhibition of old information may not itself come about intentionally but, rather, may be the by-product of participants' adopting the intention to prioritize search for new items. In Watson and Humphreys (2000), the evidence for inhibition decreased when observers did not participate in a search task, but this may reflect the absence of prioritizing the selection of new items, rather than a failure to intentionally inhibit old items. Once participants attempt to prioritize new items, old stimuli may be inhibited in a relatively automatic way. There would then be some cost for targets that share the inhibited properties of the old items (see also Gibson \& Jiang, 2001, for further supportive evidence for these suggestions). Thus, feature-based inhibition could be, to some degree, an inevitable consequence of simply trying to ignore all the first items (irrespective of color) or setting oneself to prioritize the new items.

Another possibility is that participants do adopt an intentional inhibitory state but that this is applied to the locations and/or the shapes of the old items. However, once applied, there may be inhibition of all the proper- ties of the stimuli that occur there or have those shapes. Color inhibition may be a by-product of intentional inhibition of another attribute (e.g., location). Indeed, all the preview conditions here showed large improvements relative to the full-set baselines, irrespective of the color manipulations being used; this may indicate a locationbased component of the marking mechanism, independent of any color effect (see Figure 10).

Finally, the impressive search advantages from knowing what color the target would be (e.g., in the fullp and

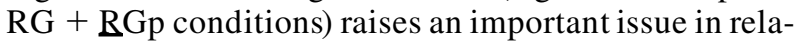
tion to standard conjunctive search (e.g., the baseline used by Watson \& Humphreys, 1997). In a search display where distractors consist of, say, green $\mathrm{Hs}$ and blue As (and the target is a blue $\mathrm{H}$ ), why do participants seem unable to simply set themselves to search the blue items and make their usual present/absent decision just on the basis of these items? In other words, if the target is never green, why search the green items at all in these tasks? One reason may be the relative discriminability of the features present in the display. In most cases, Hs and As differ in terms of shape only by one horizontal feature element, and the blue and green colors were chosen to be very similar in color space (e.g., a blueish green/greenish blue, etc.). This may mean that discrimination along both dimensions is very difficult or, possibly, that the difficult discrimination along one dimension (e.g., color) may mean observers have to rely on the shape dimension more (e.g., Sobel \& Cave, in press; Theeuwes, 1994). In our experiments here, we used heterogeneous letter shapes, which may have led to a greater reliance on color to segregate the displays than is commonly found in typical conjunction search tasks.

\section{REFERENCES}

Allport, D. A. (1993). Attention and control: Have we been asking the wrong questions? In D. E. Meyer \& S. Kornblum (Eds.), Attention and performance XIV: Synergies in experimental psychology, artificial intelligence, and cognitive neuroscience (pp. 183-218). Cambridge, MA: MIT Press.

Bacon, W. F., \& Egeth, H. E. (1994). Overriding stimulus-driven attentional capture. Perception \& Psychophysics, 55, 485-496.

Bacon, W. F., \& Egeth, H. E. (1997). Goal-directed guidance of attention: Evidence from conjunctive visual search. Journal of Experimental Psychology: Human Perception \& Performance, 23, 948-961.

Braithwaite, J. J., Humphreys, G. W., \& Hodsoll, J. (2002). Ignoring color over time: The selective effects of color on preview-based visual search of static items. Manuscript submitted for publication.

Braithwaite, J. J., Humphreys, G. W., \& Hodsoll, J. (in press). Color grouping in space and time: Evidence from negative color-based carry-over effects in preview search. Journal of Experimental Psychology: Human Perception \& Performance.

Bravo, M. J., \& NaKayama, K. (1992). The role of attention in different visual-search tasks. Perception \& Psychophysics, 51, 465-472.

Broadbent, D. E. (1958). Perception and communication. Oxford: Pergamon.

Cave, K. R. (1999). The FeatureGate model of visual selection. Psychological Research, 62, 182-194.

CAve, K. R., \& Wolfe, J. M. (1990). Modeling the role of parallel processing in visual search. Cognitive Psychology, 22, 225-271.

Donk, M., \& Theeuwes, J. (2001). Visual marking beside the mark: Prioritizing selection by abrupt onsets. Perception \& Psychophysics, 63, 891-900. 
Duncan, J., \& Humphreys, G. W. (1989). Visual search and stimulus similarity. Psychological Review, 96, 433-458.

Egeth, H. E., Virzi, R. A., \& Garbart, H. (1984). Searching for conjunctively defined targets. Journal of Experimental Psychology: Human Perception \& Performance, 10, 32-39.

Folk, C. L., \& Remington, R. W. (1996). When knowledge does not help: Limitations on the flexibility of attentional control. In A. F. Kramer (Ed.), Converging operations in the study of visual selective attention (pp. 271-297). Washington, DC: American Psychological Association.

Folk, C. L., Remington, R., \& Johnston, J. C. (1992). Involuntary covert orienting is contingent on attentional control settings. Journal of Experimental Psychology: Human Perception \& Performance, 18, 1030-1044.

Folk, C. L., Remington, R, \& Johnston, J. C. (1993). Contingent attentional capture: A reply to Yantis (1993). Journal of Experimental Psychology: Human Perception \& Performance, 19, 682-685.

Folk, C. L., Remington, R. W., \& Wright, J. H. (1994). The structure of attentional control: Contingent attentional capture by apparent motion, abrupt onset, and color. Journal of Experimental Psychology: Human Perception \& Performance, 20, 317-329.

GiBSON, B. S., \& JiANG, Y. (2001). Visual marking and the perception of salience in visual search. Perception \& Psychophysics, 63, 59-73.

Gibson, B. S., \& Kelsey, E. M. (1998). Stimulus-driven attentional capture is contingent on attentional-set for displaywide visual features. Journal of Experimental Psychology: Human Perception \& Performance, 24, 699-706.

Hillstrom, A. P., \& YANTis, S. (1994). Visual motion and attentional capture. Perception \& Psychophysics, 55, 399-411.

Humphreys, G. W., Watson, D. G., \& Joliceur, P. (2002). Fractionating visual marking: Dual-task decomposition of the marking state by timing and modality. Journal of Experimental Psychology: Human Perception \& Performance, 28, 640-660.

Kaptein, N. A., Theeuwes, J., \& van der Heijden, A. H. C. (1995). Search for a conjunctively defined target can be selectively limited to a color-defined subset of elements. Journal of Experimental Psychology: Human Perception \& Performance, 21, 1053-1069.

KIM, M.-S., \& CAVE, K. R. (1999). Top-down and bottom-up attentional control: On the nature of interference from a salient distractor. Perception \& Psychophysics, 61, 1009-1023.

KIM, M.-S., \& CAVE, K. R. (2001). Perceptual grouping via spatial selection in a focused-attention task. Vision Research, 41, 611-624.

KLEIN, R. (2000). Inhibition of return. Trends in Cognitive Sciences, 4 , 138-145.

Koshino, H. (2001). Activation and inhibition of stimulus features in conjunction search. Psychonomic Bulletin \& Review, 8, 294-300.

KWAK, H.-W., \& EGETH, H. (1992). Consequences of allocating attention to locations and to other attributes. Perception \& Psychophysics, 51, 455-464.

Moore, C. M., \& EgETh, H. (1998). How does feature-based attention affect visual processing? Journal of Experimental Psychology: Human Perception \& Performance, 24, 1296-1310.

NeISSER, U. (1967). Cognitive psychology. New York: Appleton-CenturyCrofts.

Neumann, E., \& DeSchepper, B. G. (1991). Costs and benefits of target activation and distractor inhibition in selective attention. Journal of Experimental Psychology: Learning, Memory, \& Cognition, 17, 1136-1145.

Olivers, C. N. L., \& Humphreys, G. W. (2002). When visual marking meets the attentional blink: More evidence for top-down limited capacity inhibition. Journal of Experimental Psychology: Human Perception \& Performance, 28, 22-42.

Olivers, C. N. L., Humphreys, G. W., Heinke, D., \& Cooper, A. C. G. (2002). Prioritization in visual search: Visual marking is not dependent on a mnemonic search. Perception \& Psychophysics, 64, 540-560.

Olivers, C. N. L., Watson, D. G., \& Humphreys, G. W. (1999). Visual marking of locations and feature maps: Evidence from withindimension defined conjunctions. Quarterly Journal of Experimental Psychology, 52A, 679-715.

Poisson, M. E., \& Wilkinson, F. (1992). Distractor ratio and grouping processes in visual search. Perception, 21, 21-38.
Snyder, J. J., \& Kingstone, A. (2000). Inhibition of return and visual search: How many separate loci are inhibited? Perception \& Psychophysics, 62, 452-458.

Sobel, K. V., \& CAVE, K. R. (in press). The role of salience and strategy in conjunction search. Journal of Experimental Psychology: Human Perception \& Performance.

Theeuwes, J. (1992). Perceptual selectivity for color and form. Perception \& Psychophysics, 51, 599-606.

Theeuwes, J. (1993). Visual selective attention: A theoretical analysis. Acta Psychologica, 83, 93-154.

Theeuwes, J. (1994). Stimulus-driven capture and attentional set: Selective search for color and visual abrupt onsets. Journal of Experimental Psychology: Human Perception \& Performance, 20, 799-806.

Theeuwes, J. (1996). Perceptual selectivity for color and form: On the nature of the interference effect. In A. F. Kramer, M. G. H. Coles, \& G. D. Logan (Eds.), Converging operations in the study of visual selective attention (pp. 297-315). Washington, DC: American Psychological Association.

Theeuwes, J., Kramer, A. F., \& Atchley, P. (1998). Visual marking of old objects. Psychonomic Bulletin \& Review, 5, 130-134.

Tipper, S. P. (1985). The negative priming effect: Inhibitory effects of ignored primes. Quarterly Journal of Experimental Psychology, 37A, 571-590.

Tipper, S. P., Brehaut, J. C., \& Driver, J. (1990). Selection of moving and static objects for the control of spatially directed action. Journal of Experimental Psychology: Human Perception \& Performance, 16, 492-504.

Tipper, S. P., Driver, J., \& Weaver, B. (1991). Object centered inhibition of return of visual attention [short report]. Quarterly Journal of Experimental Psychology, 43A, 289-298.

Tipper, S. P., Weaver, B., \& Houghton, G. (1994). Behavioural goals determine inhibitory mechanisms of selective attention. Quarterly Journal of Experimental Psychology, 47A, 841-864.

Treisman, A. (1993). The perception of features and objects. In A. Baddeley \& L. Weiskrantz (Eds.), Attention: Selection, awareness and control. A tribute to Donald Broadbent (pp. 5-35). New York: Oxford University Press.

Treisman, A., \& Gelade, G. (1980). A feature integration theory of attention. Cognitive Psychology, 12, 97-136.

Treisman, A., \& Sato, S. (1990). Conjunction search revisited. Journal of Experimental Psychology: Human Perception \& Performance, 16, 459-478.

Treue, S., \& Martinez Trujillo, J. C. (1999). Reshaping neuronal representations of visual scenes through attention. Current Psychology of Cognition, 18, 951-972.

Watson, D. G., \& Humphreys, G. W. (1997). Visual marking: Prioritizing selection for new objects by top-down attentional inhibition of old objects. Psychological Review, 104, 90-122.

Watson, D. G., \& Humphreys, G. W. (1998). Visual marking of moving objects: A role for top-down feature-based inhibition in selection. Journal of Experimental Psychology: Human Perception \& Performance, 24, 1-17.

Watson, D. G., \& Humphreys, G. W. (2000). Visual marking: Evidence for inhibition using a probe-dot detection paradigm. Perception \& Psychophysics, 62, 471-481.

Watson, D. G., \& Humphreys, G. W. (2002). Visual marking and visual change. Journal of Experimental Psychology: Human Perception \& Performance, 28, 379-395.

Yantis, S. (1993a). Stimulus-driven attentional capture. Current Directions in Psychological Science, 2, 156-161.

YANTIS, S. (1993b). Stimulus driven attentional capture and attentional control settings. Journal of Experimental Psychology: Human Perception \& Performance, 19, 676-681.

YANTIS, S. (1996). Attentional capture in vision. In A. F. Kramer, M. G. H. Coles, \& G. D. Logan (Eds.), Converging operations in the study of visual selective attention (pp. 45-77). Washington, DC: American Psychological Association.

Yantis, S., \& Egeth, H. (1999). On the distinction between visual salience and stimulus-driven attentional capture. Journal of Experimental Psychology: Human Perception \& Performance, 25, 661-676. Yantis, S., \& Hillstrom, A. P. (1994). Stimulus-driven attentional 
capture: Evidence from equiluminant visual objects. Journal of Experimental Psychology: Human Perception \& Performance, 20, $95-$ 107.

YANTIS, S., \& Johnston, J. C. (1990). On the locus of visual selection: Evidence from focused attention tasks. Journal of Experimental Psychology: Human Perception \& Performance, 15, 135-149.

YANTIS, S., \& JoNIDES, J. (1984). Abrupt visual onsets and selective attention: Evidence from visual search. Journal of Experimental Psychology: Human Perception \& Performance, 10, 601-621.

Zohary, E., \& Hochstein, S. (1989). How serial is serial processing in vision? Perception, 18, 191-200.

\section{NOTES}

1. The term attentional capture has been used differently by different researchers over the years. For clarity, we take here the strongly involuntary definition of capture offered by Yantis (1996; see also Donk $\&$ Theeuwes, 2001). We later introduce the term prioritized attentional capture, which can be taken as analogous to what Yantis (1996) referred to as a weaker form of capture, since it is dependent to some degree on the observer's state of attentional readiness.

2 . In the context of the present preview experiments, the anticipatory set is often referred to as a positive anticipatory set. This terms helps to clarify both that it is facilitatory in function and that it is somewhat distinct from the dual negative (inhibitory) process also taking place.

3. Braithwaite et al. (2002) ran a baseline experiment in which there were $75 \%$ of the items in one color and $25 \%$ in the other color. Despite this, there was no difference between RTs to targets in the majority or the minority color [the main effect of ratio was not significant; $F(1,15)=0.00, p=.982]$. The main effect of display size was significant $[F(1,15)=93.50, p<.001]$. The ratio $\times$ display size interaction did not approach significance $[F(1,15)=0.64, p=.424]$.
4. Indeed, there was some evidence that search in the $R+G$ condition was more efficient than that for minority targets in the $\mathrm{R}+\mathrm{RG}$ condition (a nonreliable difference of $48 \mathrm{msec}$ ).

5 . The overall mean difference for minority versus majority targets (in the second set) was $201 \mathrm{msec}$, with new minority targets being slower ( $380 \mathrm{msec}$ at the largest display size of 24 items). This produced a main effect both of color set $[F(1,16)=23.392, p<.001]$ of display size $[F(1,16)=74.255, p<.001]$, and a significant interaction between these factors $[F(1,16)=22.264, p<.001]$.

6 . In relation to the $\mathrm{R}+\mathrm{RG}$ condition, the finding that $\mathrm{RT}$ s for green targets in $R+R G$ were much longer relative to red targets in the $\mathrm{G}+$ $\underline{R} G p$ condition shows again that stimulus dimensions (e.g., simple small group capture in a bottom-up sense for green items) were not responsible for the reduced improvements in the $\mathrm{R}+\underline{\mathrm{R} G p}$ condition. This again shows that the uneven color bias was not crucial for the present results.

7. It is also important to note that, in many studies, the minority group has been confounded with the target relevant feature group, when foreknowledge has been given (e.g., Bacon \& Egeth, 1997; Egeth et al., 1984). Here, the RG + G (from Experiment 1) and the $R+\underline{R} G p$ (from Experiment 2) conditions are exceptions to this often overlooked factor. The relevant target feature was also, once both displays were present, the majority group. The fact that these conditions provided completely different search performances indicates that something other than just unequal color groups was influencing search.

8. This notion is also consistent with other paradigms revealing a time course difference for capture and the later spread or involvement of feature-based inhibition (e.g., Kim \& Cave, 1999, 2001).

(Manuscript received July 9, 2001; accepted for publication September 2, 2002.) 